\title{
Numerical Investigation of the In-Plane Seismic Performance of Unstrengthened and TRM-Strengthened Rammed Earth Walls
}

\author{
Reza Allahvirdizadeh*, Daniel V. Oliveira, Rui A. Silva \\ ISISE, Institute of Science and Innovation for Bio-Sustainability (IB-S), Department of Civil Engineering, \\ University of Minho, Guimarães, Portugal
}

\begin{abstract}
:
The large availability of raw earth around the World led to its extensive use as a building material through history. Thus, earthen materials integrate several historical monuments, but their main use was to build living and working environments for billions of people. On the other hand, past earthquakes revealed their inadequate seismic behavior, which is a matter of concern as a significant percentage of earthen buildings are located in regions with medium to high seismic hazard. Nevertheless, their seismic behavior and the development of efficient strengthening solutions are topics that are not yet sufficiently investigated in the literature. In this context, this study investigates numerically the in-plane seismic behavior of a rammed earth component by means of advanced nonlinear finite element modelling, which included performing nonlinear static (pushover) and nonlinear dynamic analyses. Moreover, the strengthening effectiveness of a low-cost textile reinforced mortar on such component was also evaluated. The strengthening was observed to increase the load and displacement capacities, to preserve the integrity for higher lateral load levels and to postpone failure without adding significant mass to the system. Furthermore, the pushover analysis was shown to predict reliably the capacities of the models with respect to the incremental dynamic analysis.
\end{abstract}

Keywords: Rammed Earth; Strengthening; Textile Reinforced Mortar; In-plane Behavior; Numerical Modelling; Pushover Analysis; Nonlinear Time-History Analysis.

\section{Introduction}

Different building techniques were developed since the life-style of mankind shifted from nomadic to sedentary. The development of these techniques was mainly promoted by the new materials readily available in the settling region, meaning that most of them relied in the use of raw earth, stone and timber. Among the many earth-based building techniques developed through time, adobe masonry and rammed earth are probably among the most well-known ones and widespread in the world (Houben and Guillaud 1994).

"Corresponding Author, email: allahvirdizadeh@gmail.com 
Building in rammed earth consists in compacting layers of earth with adequate particle size distribution and moisture inside two parallel shutters to erect walls (Miccoli et al. 2014). The strength of the material is governed by binding forces due to capillary suction originated at the porous structure of the material with drying (Jaquin et al. 2008) as well as by the friction and interlocking capacity of the coarse particles (Silva et al. 2016 and Silva et al. 2018a). Nowadays, stabilization with cement is a procedure typically used to improve the properties of rammed earth, as a consequence of binding mechanisms associated to the formation of cementitious gels. Nevertheless, lime stabilization has an historical relation with rammed earth, as for instance this procedure was used to build several fortresses in the Iberian Peninsula centuries ago (González 1999). The compaction was traditionally performed with manual rammers, while nowadays this process is facilitated by the use of mechanic equipment, such as pneumatic rammers (Minke 2006).

Regarding the origin of rammed earth, Jaquin et al. (2008) argues that it was independently developed in China and in Mediterranean region and later on was spread by the settlers of the new World. This universality of rammed earth gave origin to different names according to the country, namely Taipa in Portugal, Tapial in Spain, Pisé in France, Terra Battuta in Italy, Stampflehm in Germany, Chineh in Iran, Hangtu in China and Pakhsa in Uzbekistan (Jaquin et al. 2008).

Several monuments made of earth can be found around the world. Nevertheless, the large availability and low cost of the material were the main reasons why it constituted an appropriate choice for sheltering societies with economic issues, as well as for hardly accessible regions and isolated rural areas. The fact is that the extensive use of raw earth as building material resulted in about $33 \%$ of the world population estimated to live in such environments in the nineteen eighties (Houben and Guillaud 1994). Since then, this percentage has been dropping, but the recent pursue for more sustainable building solutions, led to a renewed interest for this type of constructions. Hence, the investigation of the structural performance of earth constructions is vital to provide tools that grant the adequate assessment of the safety of new and existing constructions.

Several factors such as rainwater, soluble salts and temperature oscillations can lead to occurrence of damage in rammed earth constructions (Parreira 2007). Furthermore, these constructions are significantly vulnerable to earthquakes, as they are mainly built to withstand gravity loads. The low tensile strength, lack of continuity at corners and wall connections, the occurrence of concentrated roof loads, the absence of ring beams, discontinuity between roof and walls, existence of long walls, absence of proper foundation, poor lintel supports, irregularity on the opening distribution and existence of opening close to corners constitute the main factors contributing to high seismic vulnerability of rammed earth constructions (Correia et al. 2015). In spite of such weaknesses, it was observed that an important percentage of these buildings is located in regions with medium to high seismic hazard (De Sensi 2003), which caused many inhabitants and historical monuments to be 
severely affected by occurrence of earthquakes. An approximate estimation revealed that about $60 \%$ of fatalities in earthquakes during the second half of the last century were attributed to failure of unreinforced masonry components (Coburn 2002). For instance, the destruction of the historical citadel of Arg-e-Bam by the 2003 earthquake is one of the most catastrophic cases demonstrating the high seismic vulnerability of earthen constructions, namely of adobe masonry.

Regarding the seismic vulnerability of rammed earth structures, some numerical and experimental studies have been previously conducted to assess the seismic performance of rammed earth constructions. Most of the experimental studies are limited to the component level (wallets) by conducting uniaxial or diagonal compression tests to characterize material properties and investigate its local behavior (see Yamin et al. 2004; Miccoli et al. 2014; Miccoli et al. 2015; Bui and Morel 2009). With respect to the full-scale building, Bui et al. (2011) employed the frequency domain decomposition procedure to extract dynamic properties of rammed earth structures from in-situ dynamic identification tests. It was concluded that Eurocode 8 equation for estimating the fundamental period of the building would be still valid for rammed earth buildings and that their damping ratio may vary between $2.5-4.0 \%$. In addition, Wang et al. (2016) tested on shaking table a model of a typical rural rammed earth building with one story. It was observed that the failure was characterized by out-of-plane rotation, cracking at the corners and at the loading points where the roof load was transferred to the walls.

Regarding the numerical studies, three main different strategies have been employed so far, namely simplified (using limit analysis), finite element (FE) and discrete element (DE) modeling. Ciancio and Augarde (2013) proposed static (elastic analysis) and kinematic (ultimate strength analysis) approaches to evaluate the out-of-plane wind capacity of rammed earth walls. However, the simplifications introduced by such models may not be representative of real conditions and behavior. Regarding FE modeling, micro- and macro-modeling approaches were used in Miccoli et al. (2014) to simulate the response of rammed earth wallets tested under uniaxial and diagonal compression. In this case, it was concluded that both methods showed a good agreement against experimental responses. Hence, the interface between layers can be ignored and homogenous material properties can be assumed in the whole rammed earth component. Allahvirdizadeh et al. (2018) used the macromodeling approach to evaluate the out-of-plane seismic performance of a rammed earth subassembly. It was shown that plain walls may fail due to detachment from orthogonal walls and bend over their mid-section. DE modeling is less used than FE modeling, though it was adopted in Bui et al. (2015) to take into account the influence of the layers on the structural behavior of rammed earth components. Similarly to FEM, it was concluded that the results obtained by models with or without interfaces between layers were similar, even when very low interface parameters were considered. 
101 The literature on earthen structures has been also focused on the investigation of adequate 102 strengthening solutions, which aim mainly at reducing their seismic vulnerability. In this regard, it is 103 recommended to implement repair works before applying strengthening solutions. Erosion and cracking are typical damage types found in earthen walls, which can be repaired by local rebuilding and injection of compatible grouts (Figueiredo et al. 2013; Silva et al. 2016 and Illampas et al. 2017). With respect to strengthening, several solutions have been proposed, namely the use of boundary wooden elements tying of the walls, introduction of ring beams, and application of composite-based materials (Figueiredo et al. 2013; Yamin et al. 2004).

The strengthening of masonry with composite-based solutions has been receiving a great attention in the last two decades, especially with respect to the use of solutions based on fiber reinforced polymers (FRP). The popularity of FRP-based strengthening was driven by its significant efficiency in increasing the shear/flexural capacity and ductility of components with a negligible increase in mass (high strength and stiffness to weight ratio) and ease of application. In other words, this technique can strongly improve the weak tensile strength of masonry and prevent or postpone the occurrence of brittle failure. Despite that, it presents several drawbacks, such as poor fire/high-temperature resistance (low glass transition temperature), lack of vapor permeability, low reversibility, high cost and incompatibility with masonry substrate (Papanicolaou et al. 2008; Valluzzi et al. 2014; Michels et 118 al. 2015).

119 Most of these issues result from using organic matrices in the application process. Therefore, alternative techniques have been developed in order to integrate more compatible matrices such as cement- or lime-based mortars. Moreover, sheets are substituted by mesh grids to grant a good embedment and bond to the support. These alternatives are known as Steel Reinforced Grout (SRG), Fiber Reinforced Cementitious Matrix (FRCM) or Textile Reinforced Mortar (TRM). It is evident that their effective application requires understanding their behavior, both at the level of characteristics of the constituent materials and their interaction. In this regard, several experimental studies have been conducted to characterize material properties of composite materials and to investigate its influence on the performance of masonry components (see Papanicolaou et al. 2007; De Felice et al. 2014; Ascione et al. 2015; Mordanova et al. 2016; Garofano et al. 2016; Mininno et al. 2017). However, most of the research conducted so far on strengthening of masonry walls with TRM is addressed to brick masonry rather than rammed earth.

In this context, the current study presents a numerical investigation on the in-plane behavior of an unstrengthened and TRM-strengthened rammed earth wall by means of an advanced nonlinear finite element model. The outcomes of this study will be used to design an experimental program on an 
135

136

137

138

139

140

141

142

143

144

145

146

147

148

149

150

151

152

153

154

155

156

157

158

160

161

162

163

164

165

166

rammed earth walls subjected to dynamic loading and on the strengthening efficiency of the TRM technique.

\section{Model Definition}

In order to reliably assess the in-plane seismic performance of rammed earth walls and also evaluate the strengthening effectiveness of TRM on enhancing their behavior, it is essential to consider a representative geometry and construct valid numerical models. For this purpose, an unstrengthened and a TRM-strengthened models were considered for numerical analysis. This section addresses the main aspects regarding the definition of such models, namely in terms of geometry, nonlinear material models and meshing considerations. Furthermore, it should be noted that the models were implemented and computed using DIANA 10.1 software (DIANA FEA BV 2017).

\subsection{Geometry}

An I-shaped geometry was idealized to investigate the in-plane seismic performance of the rammed earth walls. The web wall transfers lateral loads, while the wing walls are only necessary for stability objectives during the experimental program, which is planned to be designed in near future based on outcomes of the current study. Therefore, the wing walls are required to avoid changing the desired failure mode of the model, which is discussed in detail in the following sections.

Furthermore, the definition of the geometry of the model demands satisfying observable conditions (be compatible with real rammed earth buildings) and limitations of the experimental facilities. Hence, the outcomes of previous surveys on rammed earth dwellings located in Alentejo region (southern Portugal) were taken into account (Correia 2007 and Dominguez 2015). This region presents an expressive number of rammed earth dwellings (see Fig. 1), thus the statistical analysis of the different in-plane components identified from the aforementioned survey is expected to provide valid dimensions for the model.

(a)

(b)

Fig. 1. Rammed earth constructions in Portugal: (a) Alentejo region (in red); (b) examples of typical dwellings (Silva et al. 2018b)

The average height and length of the surveyed buildings are presented in Fig. 2. As it can be seen, the average height and length values are $2.20 \mathrm{~m}$ and $3.75 \mathrm{~m}$, respectively. Moreover, the thickness of the walls was in all cases of about $0.5 \mathrm{~m}$, which led to consider this same value in this study. Considering 
the observed values (and also the limitations of the testing facilities), two geometries were defined as illustrated in Fig. 3. It is worthwhile to note that all dimensions of the considered models are identical, excepting the length of their wing walls. It is expected that such difference affects the failure mode of the web walls. It should be noted that the wing walls are very important in the experimental setup due to stability concerns. The considered geometries result in components with a weight of approximately $134 \mathrm{kN}$ and $160 \mathrm{kN}$ (assuming density equal to $2000 \mathrm{~kg} / \mathrm{m}^{3}$ ) for the model with $50 \mathrm{~cm}$ and $80 \mathrm{~cm}$ wing walls, respectively. The final component is aimed to be tested on a shaking table, which allows for a maximum mass of about 21 tons and plan dimensions of about $5.6 \times 4.6 \mathrm{~m}^{2}$.

Fig. 2. Average length and height of the rammed earth walls identified in the surveyed rammed earth dwellings

(a) Fig. 3. Considered in-plane models: (a) $50 \mathrm{~cm}$ long wing walls (b) $80 \mathrm{~cm}$ long wing walls

\subsection{Material Properties}

Conducting advanced FE analyses requires assigning representative properties to the materials considered to contribute to the structural behavior, as well as to the several levels of interaction between them (see Fig. 4). In order to balance reliability with computational power requirements, the current study adopted the macro-modeling approach, meaning that the rammed earth and the strengthening composite system (mesh and mortar) were assumed with homogenized properties. As previously discussed, ignoring the influence of the interfaces between rammed earth layers is not expected to significantly affect the obtained outcomes, despite being preferential surfaces for cracking development and failure. The simplification assumed for the strengthening composite prevents the simulation of the sliding failure mode of the mesh within the mortar, which can be a non-negligible aspect when longitudinal and transversal yarns are not welded at the nodes. Furthermore, the connection between the rammed earth and the mortar was assumed as perfectly bonded, meaning that the model is not able to simulate debonding failure. These failure modes are expected to affect the local behavior of the strengthening; nevertheless the total absence of reliable experimental data on bond behavior of TRM-strengthened rammed earth justifies the assumed simplifications.

\footnotetext{
Fig. 4. Detailed view of the materials and interaction levels contributing for the structural behavior of the
} unstrengthened and strengthened models 


\subsubsection{Rammed Earth}

From a general point of view, rammed earth presents a fragile response under tension due to low tensile strength values, meaning that its seismic response is expected to be controlled by cracking mechanisms. In this regard, the use of smeared cracking models is expected to result in adequate simulation of the mechanical behavior of rammed earth (see Silva et al. 2014; Librici 2016 and Allahvirdizadeh 2017). Thus, the total strain rotating crack model (TSRCM) implemented in DIANA 10.1 (DIANA FEA BV 2017) was used to simulate the rammed earth material of the models. In this model the crack initiates when the principal tensile stress reaches the tensile strength of the material and its direction rotates according to the direction of the principal tensile strain. Furthermore, in the post-peak region, the tensile strength degrades following the predefined softening rule (in this study an exponential curve is adopted). Furthermore, it should be noted that the unloading and reloading of the TSRCM (hysteretic behavior) is simulated by a secant approach, meaning that unloading/reloading is processed to/from the origin, respectively.

Identifying the nonlinear mechanical properties of rammed earth is still a fundamental challenge within the investigation of this type of structures, as there are different parameters affecting them, such as particle size distribution, moisture content, compaction (rate and type), void ratio, cohesive strength of particles, fiber content, and quantity and type of additions. Thus, the values available in the literature present high scattering (see Liley and Robinson 1995; Yamin et al. 2004; Parreira 2007; Maniatidis et al. 2007; Bui and Morel 2009; Miccoli et al. 2014).

Previous studies revealed the expressive nonlinear behavior of rammed earth under compression, which initiates at very low stress levels (Silva 2013). Such behavior led conventional parabolic relationships typically used to simulate concrete and masonry to be deemed as inadequate for rammed earth, as they result in excessively rigid behaviors that do not portray adequately the nonlinear behavior of the rammed earth. Adopting a multi-linear relationship extracted from average of results of uniaxial tests was shown to lead acceptable outcomes instead (Miccoli et al. 2015; Librici 2016). Thus, the current numerical investigation adopted a previously calibrated multi-linear stress-strain relationship in compression (Silva et al. 2014), portrayed in Fig. 5. The experimental results used to obtain this relationship were obtained from compression tests on rammed earth cylindrical specimens, which were made of soil collected from Alentejo region (Silva et al. 2016). It should be noted that due to lack of results in the post-peak phase, its development was idealized by assuming a linear trend of the experimental data obtained.

Fig. 5. Adopted compressive behavior of the rammed earth material 
234 Regarding the tensile behavior, an exponential relationship was taken into account. This relationship

235 is defined by the tensile strength $\left(f_{t}\right)$ and mode-I tensile fracture energy $\left(G_{f}{ }^{I}\right)$. These parameters were 236 assumed with basis on the calibrated model presented in Silva et al. (2014), from which the values 237 considered for the tensile strength and mode-I tensile fracture energy were $0.05 \mathrm{MPa}$ and 0.074 $238 \mathrm{~N} / \mathrm{mm}$, respectively. The crack bandwidth was assumed as the square root of the element area $(A)$ to 239 make the numerical outcomes independent from the size of the element.

240 Finally, the density adopted for the rammed earth was of $2000 \mathrm{~kg} / \mathrm{m}^{3}$, while a Poisson's ratio of 0.27 241 was assumed considering the calibrated model presented in Silva et al. (2014).

\subsubsection{TRM strengthening}

244 One of the objectives of the current study is to investigate the TRM strengthening effect on rammed earth walls subjected to in-plane loading. The implementation of this type of strengthening on rammed earth requires adopting a compatible solution, which is being investigated in the framework of the project SafEarth (Barroso 2017; Oliveira et al. 2017 and Sadeghi et al. 2017). This type of strengthening also aims to be affordable in order to facilitate its dissemination, meaning that low cost meshes are being proposed to integrate this composite material. Thus, the selected solution is hereinafter called as low-cost textile reinforced mortar (LC-TRM) and it consists of a low-cost glass fiber mesh embedded in an earth-based mortar, whose characterization of materials and composite behavior is detailed elsewhere (Barroso 2017). In brief, the solution adopted in this study presents the highest values of tensile strength and stiffness among the solutions characterized in the aforementioned study.

The outcomes of uniaxial tensile tests on mesh-mortar coupons (Barroso 2017) were used to define the tensile behavior of the adopted LC-TRM strengthening, by averaging the experimental response curves. In compression, the contribution of the mesh was ignored and the average response curve of mortar specimens tested under compression was adopted (Barroso 2017) to simulate the behavior of the LC-TRM. Both tensile and compressive behaviors were simulated using multi-linear relationships, as illustrated in Fig. 6. The tensile behavior is characterized by a trilinear relationship that simulates the three stages typically observed in TRM, namely uncracked, crack development and cracked (see Ascione et al. 2015). The lack of experimental data in the post-peak phase of the mortar tested in compression led also to idealize a linear trend to complete the curve. The TSRCM (DIANA FEA BV 2017) was also used to simulate the material behavior of the selected LC-TRM composite. The adopted mechanical properties of the LC-TRM are presented in Fig. 6. The bulk density and Poisson's ratio of the LC-TRM were considered as $1810 \mathrm{~kg} / \mathrm{m}^{3}$ and 0.27 , respectively. 
267

268

269

270

271

272

273

274

275

276

277

278

279

280

281

282

283

284

285

286

287

288

289

290

291

292

293

294

295

296

297

To the knowledge of authors, there is no experimental study available on the performance of TRMstrengthened rammed earth walls subjected to lateral loads. In spite of that, the adopted modelling approach was satisfactorily used in previous studies to predict the seismic performance of TRMstrengthened masonry panels (Basili et al. 2016).

Fig. 6. Adopted stress-strain behavior of the LC-TRM strengthening

\subsection{Meshing}

The modeling of the unstrengthened structural component was evaluated initially by means of two meshing strategies, namely by considering solid and shell elements. Shell elements are widely used in the modeling of masonry structures with the advantage of requiring lower computational demand. However, the considerable thickness of rammed earth walls in comparison to the other dimensions creates doubts on the reliability of shell elements. This concern was evaluated by comparing the use of both element types. It is worth mentioning that the shell models were prepared considering the midsection planes of each wall, as presented schematically in Fig. 7. This strategy evidently presents limitations, namely with regard to the simulation of the connection between walls (assumed as infinite rigid) and of the correct length of the wing walls (higher lengths are assumed). Furthermore, the overlapping thickness of the walls leads to a wrong consideration of the real self-weight value and mass distribution, and thus of the inertial forces. These limitations are expected to have influence on the response of the models.

Fig. 7. Schematic view of the shell models

Generally, three types of elements were adopted for meshing the unstrengthened and strengthened models. For the rammed earth, 20 nodes iso-parametric brick elements (designated by CHX60) were used in the solid strategy, while 8 nodes quadrilateral curved shell elements (denoted as CQ40S) were used for the shell strategy and for meshing the TRM strengthening. Moreover, $8+8$ nodes quadrilateral rigid interface elements were adopted for the interface between strengthening and wall (called as CQ48I). These elements are shown in Fig. 8. It should be noted that the default integration scheme $3 \times 3 \times 3$ was used for the solid elements, while the $2 \times 2$ scheme was used for the shell ones, where the integration along the thickness considered 7 layers.

(a)

Fig. 8. Types of elements employed in the preparation of the models:

(DIANA FEA BV 2017) (c)

: (a) CHX60 (b) CQ40S (c) CQ48I 
300 Proper selection of the meshing size is necessary to obtain accurate results and relatively adequate 301 computational times. In this regard, three meshing sizes were tested in the models, namely $25 \mathrm{~mm}$ 302 (over-meshed), $50 \mathrm{~mm}$ and $100 \mathrm{~mm}$. The accuracy of the selected meshing sizes was evaluated in the unstrengthened model by comparing the outcomes under both self-weight and in-plane pushing. It was observed that the model with the meshing size equal to $100 \mathrm{~mm}$ results in less than $1 \%$ error (both in terms of base shear and displacements) with respect to the over-meshed model. Thus, the $100 \mathrm{~mm}$ mesh size was used in the subsequent numerical investigation.

The models were validated by comparing the obtained reactions under gravity load (self-weight of the walls) with the weight computed with basis on the geometry and density of the rammed earth. The solid models accurately predicted the wall's self-weight, while the shell models result in an error of about $7 \%$ due to the previously referred geometric limitations. The influence of the error introduced by the shell modeling approach on the dynamic properties of the rammed earth wall is also evidenced in Fig. 9, which presents the frequency ratios between the shell and solid models for the six first corresponding modes; it should be noted that the natural frequencies depend on the assembled mass and stiffness matrices of the models. The frequency ratios are clearly shown to be smaller than 1 due to the higher mass of the shell model, which results in lower frequency values. Higher modes seem to be more affected.

Fig. 9. Frequency ratios between the shell and solid models for the six first corresponding modes

\section{Pushover Analyses}

This section, presents the results of conventional mass-proportioned nonlinear static analyses (socalled pushover) performed on all considered models. First a sensitivity analysis on the material properties adopted for rammed earth was performed to evaluate their influence on the in-plane behavior. Then, the results of the considered models are discussed with respect to the loading capacity, displacement capacity and failure modes. It should be noted that pushover analysis is widely employed to assess seismic capacities both in research and practice. In spite of a simplified approach with respect to the dynamic nonlinear analyses, pushover was previously shown to reliably predict the average of the responses; however the predicted damage patterns may differ from reality (Allahvirdizadeh and Gholipour 2017).

It is worthwhile mentioning that the models were monotonically pushed only in the positive longitudinal (in-plane) direction $(+\mathrm{X})$, since their symmetric geometry leads to similar mechanical results when monotonically pushed in the negative direction (-X); see Fig. 3 for directions. 
334

335

336

337

338

339

340

341

342

343

344

345

346

347

348

349

350

351

352

353

354

355

356

357

358

359

360

361

362

363

364

Table 1. Parameters considered in the sensitivity analysis

(a)

(c)

\subsection{Sensitivity Analysis}

The sensitivity analysis was conducted by considering lower and upper values for the mechanical properties of the rammed earth, in addition to the adopted reference values. These values are reported in Table 1. It is worthwhile to note that the reference values correspond to the previously discussed values in material characterization (see sections 2.2.1 and 2.2.2); while the lower and upper values were obtained by calculating half and double of those reference values, respectively. These wide ranges of values were considered instead of narrow ranges resulting from the lower and upper bounds shown in Fig. 5 to better distinguish the most sensitive parameters. Nevertheless, the adopted ranges are still within the values reported in the literature (Miccoli et al. 2014). In the case of Young's modulus of the multi-linear compression, only the initial slope of the curve was adjusted to obtain desired values without changing compressive strength or idealized post-peak branch. Similarly, the multi-linear curve was scaled with identical initial and post-peak slopes to obtain aimed compressive strength values.

For sake of brevity, the outcomes are only presented for the unstrengthened solid model with $50 \mathrm{~cm}$ long wing walls. The results of the sensitivity analyses are presented in Fig. 10, in terms of the pushover curves (representing the normalized base shear to the weight of the wall as a function of the displacement at the top mid-section of the right wing wall). The compressive strength and the Poisson's ratio seem to have negligible influence on the behavior. The tensile fracture energy also seems to present negligible influence on the loading capacity, though it seems to control the deformation capacity in the post-peak phase. The loading capacity is not significantly affected by changing the Young's modulus, which controls the stiffness of the models, meaning that the variation of this parameter changes significantly the deformation behavior of the model. Among all tested parameters, the tensile strength seems to be the parameter affecting mostly the in-plane behavior of the model. As it is clear, the tensile strength controls both load and displacement capacities. For instance, doubling or halving the tensile strength, results in about $50 \%$ increase or decrease in lateral load capacity of the component, respectively. Furthermore, the in-plane shear failure of the rammed earth component is demonstrated to be mainly governed by cracking damage.

Fig. 10. Pushover curves obtained from the sensitivity analyses of the unstrengthened solid model with $50 \mathrm{~cm}$ wing walls: (a) Compressive strength (b) Poisson's ratio (c) Young modulus (d) Tensile strength (e) Tensile fracture energy 


\subsection{Unstrengthened Models}

In addition to the evaluation of the in-plane behavior of rammed earth components, the pushover analyses of the unstrengthened models allowed to conclude about the modeling approach (i.e. shell or solid) showing the best compromise between accuracy of results and computational effort.

The pushover curves of the models are portrayed in Fig. 11, which the lateral displacement of three nodes, namely on top of the left and right wings, and on top of the middle section of the web were considered. In all cases, the right wing (the wing which was leaned on during the push) controls the behavior. Regarding the meshing approach, the lateral displacements in the shell models are greater than those of the solid ones. Nevertheless, a minor increase in peak capacity is observed from the shell to the solid models.

The point of damage initiation of the models is also highlighted in the curves, which corresponds to the onset of the cracks' opening. As it can be seen, this state occurs for very low values of the imposed lateral loading, evidencing the great influence of the nonlinear behavior of the rammed earth on the structural behavior.

(a)

(c) (b)

Fig. 11. Pushover curves of the unstrengthened models: (a) Shell model with $80 \mathrm{~cm}$ wings (b) Solid model with $80 \mathrm{~cm}$ wings (c) Shell model with $50 \mathrm{~cm}$ wings (d) Solid model with $50 \mathrm{~cm}$ wings

The models with $50 \mathrm{~cm}$ wings achieved higher load and displacement capacities than those of the models with $80 \mathrm{~cm}$ wings. It is also true that the damage initiation occurs earlier for the models with $80 \mathrm{~cm}$ wings. This difference in behavior is explained by the influence of the out-of-plane bending of wings on the response, where the higher their length the earlier is the damage initiation due to tension cracking. Thus, a response of the models governed by the in-plane behavior of the web wall is very unlikely to be the dominant failure mode in the models with $80 \mathrm{~cm}$ wings, since these walls induce high bending stresses. These aspects are later discussed by investigating developed strains/stresses. Furthermore, it should be noted that experimental models with similar geometry to that of the numerical models are planned to be experimentally tested in near future, and that due to stability concerns during the tests the wings cannot be eliminated. Therefore, it is of utmost interest to find the dimensions that satisfy not only the experimental concerns, but also represent the desired lateral behavior of the rammed earth walls.

With respect to the failure modes evidenced by the models, when the response is considered by the left wing and the mid web nodes, it is possible to observe that an apparent unloading occurs after reaching the peak load. This situation can be explained by the possible detachment between the right 
401 wing and the web wall. Such detachment increases displacements on the right wing, whereas the left

402 wing and the web unload. It is clear that the sway of the right wing cannot be interpreted entirely as 403 ductility of the model.

404 The contour maps of the total lateral displacements in X-direction (in-plane) at the peak capacity of 405 the models are shown in Fig. 12. As it can be seen, the shell models experienced higher lateral 406 displacements at the right wing. This behavior is a consequence of the disregarded thickness of the 407 web, where the supporting effect is not simulated in its full extension, meaning that the wings are 408 considered with a longer effective length and are more easily bended. Thus, it can be stated that the 409 thickness disregarded of the shell models may lead to the prediction of unreliable failure mechanisms 410 and capacities.

Fig. 12. Total lateral displacements at the $80 \mathrm{~cm}$ long wings (b) solid model with $80 \mathrm{~cm}$

414

415

416

417

418

419

420

421

422

423

424

425

426

427 (a)

(b)

Fig. 13. Principal tensile strains at the peak capacity of the unstrengthened models: (a) shell model with $80 \mathrm{~cm}$ long wings (b) solid model with $80 \mathrm{~cm}$ long wings (c) shell model with $50 \mathrm{~cm}$ long wings (d) solid model with $50 \mathrm{~cm}$ long wings

Furthermore, the influence of transversal (wing) walls on the observed failure mode is addressed by conducting pushover analysis on a model without wing walls. By considering the control node on the middle section of the web wall the obtained pushover curve is shown in Fig. 14a. As it can be seen, 
the existence of transversal walls has a considerable influence on the in-plane load capacity of the rammed earth wall (10\% reduction); although, their effect on the displacement capacity is much more evident. The occurred failure modes were investigated by comparing the principal tensile strains of both cases, as presented in Fig. $14 \mathrm{~b}$ and c. As it is evident, the dominant failure mode is changed from detachment of wing walls, in the component with wing walls, to sliding/rocking in the model without wing walls.

\section{(a)} principal tensile strains of the unstrengthened rammed earth wall with $50 \mathrm{~cm}$ long wing walls (c) principal tensile strains of the unstrengthened rammed earth wall without wing walls

\subsection{Strengthened Models}

The LC-TRM strengthening was applied continuously on all vertical surfaces of the model, which corresponds to the situation that is expected to grant the maximum improvement capacity. The pushover curves of the strengthened model are compared with those of the unstrengthened one in Fig. 15. The strengthening slightly increased the lateral stiffness and increased considerably the loading and displacement capacities of the component. Despite that, the right wing still sways, meaning that the failure mode did not changed from the unstrengthened model to the strengthened one. By considering the control node on the right wing, the lateral displacement and load capacities of the strengthened model increased approximately $90 \%$ and $21 \%$, respectively. Nevertheless, the detachment of the right wing from the web makes the displacement of the control node on the middle section of the web a global indicator of the displacement capacity improvement introduced by the strengthening. With respect to this control node, a 57\% increase in the lateral displacement was observed. Regarding the damage initiation point, also highlighted in Fig. 15, no difference was detected with respected to the unstrengthened model. As previously discussed, this point corresponds to localized damage occurrence, thus the onset of the damage in the strengthened model is identical to that of the unstrengthened model.

Fig. 15. Pushover curves of the strengthened model

The contour maps of displacements were also investigated to understand the failure mechanism of the strengthened model (see Fig. 16). By comparing the experienced lateral displacements of the unstrengthened and strengthened models at the load factor equal to the peak capacity of the 
unstrengthened model, it is observed that the strengthened model presents lower deformations, due to increase in the lateral stiffness and a probable better stress distribution capacity. On the other hand, the contour of the strengthened model at its peak capacity shows important deformations at the right wing and in the region of its connection with the web. Therefore, it can be concluded that the failure mechanism of the strengthened model is also governed by detachment of the right wing. Furthermore, the adopted LC-TRM strengthening solution is shown to be efficient on postponing this failure mode.

(a)

(b)

(c)

Fig. 16. Total lateral displacements of the strengthened model in comparison to the plain one: (a) unstrengthened model at its peak capacity (b) strengthened model at the peak capacity of the unstrengthened model (c) strengthened model at its peak capacity

Additionally, the applied strengthening solution was expected to increase integrity of the wall by promoting the redistribution stresses and decreasing stress concentration in the most vulnerable regions, as evidenced in the contour maps of the principal tensile strains presented in Fig. 17. A diagonal strut (shear crack) was observed to form at the web of the unstrengthened model at its peak capacity, while this type of damage did not occur in the strengthened model at this point. This situation is due to the increased capacity promoted by the LC-TRM composite and by its contribution in transferring the tensile stresses. At this stage, the detachment between the right wing and the web is completely prevented. Only a small damage in the toe of the left wing was observed, evidencing the tendency of the wall to overturn. It can be also seen that the strengthened model experiences smaller strains in this region in comparison with the unstrengthened model. The principal tensile strains at the peak capacity of the strengthened model show an important detachment of the right wing, despite a portion of the web following the wing. From the kinematic point of view, this added portion means that a greater load is required to cause the right wing to detach from the wall and overturn. Moreover, a diagonal shear crack was observed in the web, whose development is much more expressive than that evidenced in unstrengthened one. This developed diagonal shear crack illustrates the mechanical efficiency of the adopted strengthening solution in improving the in-plane shear behavior of the rammed earth component.

On the other hand, it is also important to investigate the damage state of the strengthening. In this regard, the contour of the principal tensile strains at the peak capacity of the strengthened model is presented in Fig. 17d. It clearly shows the working mode of the strengthening solution. In other words, the efficient strengthening technique should mostly work in regions likely to fail without reinforcement, namely at the connection of the right wing with the web and at the diagonal of the web. Thus, it is comprehensible that considerable tensile strains developed at the strengthening adjacent to the right wing, which were responsible to postpone the detachment. 
(a)

Fig. 17. Principal tensile strains of the strengthened model in comparison to the unstrengthened one: (a) unstrengthened model at its peak capacity (b) strengthened model at the peak capacity of the unstrengthened model (c) strengthened model at its peak capacity (d) LC-TRM strengthening at peak capacity of the strengthened model

\section{Influence of the Damage on Dynamic Behavior (Modal Analysis)}

512 The initiation and development of cracks (damage) under monotonically increasing lateral loads cause the stiffness of a structure to decrease. As a consequence, the dynamic properties (i.e. frequencies and mode shapes) of the damaged models change as well. Such changes can be employed to evaluate and monitor in a simple way the damage evolution during the pushover analyses. To this purpose, stepwise modal analyses were conducted on both unstrengthened and strengthened models during the pushover analyses presented above.

The initial (undamaged) mode shapes, periods and cumulative effective mass participation (CEM) of four highest contributing modes in each principal direction ( $\mathrm{X}$ and $\mathrm{Y}$ ) of both models are reported in Table 2. As it can be seen, the introduction of the strengthening did not change the mode shapes of the component, since it introduced minor influence on the mass and stiffness. However, a slight increase on the $C E M$ and a slight reduction in periods can be distinguished.

The damage development in the models was evaluated by normalizing the frequency values obtained from different lateral loading levels (imposed during the pushover analyses) to the initial values. It is worthwhile to note that the frequencies at each imposed lateral displacement were obtained by running a modal analysis at the corresponding step considering the updated stiffness matrix. This frequency ratio was only determined up to the loading capacity of the models and is plotted as function of the displacement at the middle node on the top of the web wall (see Fig. 18). In general, the frequencies of the unstrengthened model present an exponential decrease with increasing displacement, though this reduction is smoother in the case of the strengthened model. At the loading capacity of the unstrengthened model, the frequency decreased about 11\% (average of considered modes), while in the case of the strengthened model the decrease was of about $6 \%$ for the same corresponding displacement level. This lower decrease of the frequency ratio of the strengthened model with respect to the unstrengthened one means that the LC-TRM strengthening is able to reduce the level of damage of the component for equivalent levels of deformation. 
(a)

(c) (b)

(d)

Fig. 18. Damage evolution based on the frequency ratio of the highest participating modes: (a) Mode 1 (b) Mode 4 (c) Mode 8 (d) Mode 10

\section{Nonlinear Dynamic Analyses}

543 Employing nonlinear static analyses (pushover) may lead to acceptable results of the dynamic 544 response of existing structures (Allahvirdizadeh et al. 2017); however, the predicted damage can 545 significantly differ from the more robust nonlinear dynamic analyses (Allahvirdizadeh and Gholipour 546 2017). Thus, the applicability and reliability of the pushover analyses in assessing the seismic performance of rammed earth components was evaluated by comparison with the results from nonlinear time-history analyses. In this regard, incremental dynamic analyses, so-called IDA (Vamvatsikos and Cornell 2002) were conducted by applying a series of linearly scaled ground motion records.

551 The outcomes obtained from IDA can be interpreted from two perspectives, namely force-based or displacement-based. In the former, the maximum experienced lateral force (i.e. the intensity of the applied ground motion record) and corresponding displacement are extracted from each nonlinear dynamic analysis, while the latter seeks for the maximum experienced lateral displacement and corresponding lateral force. In general, a reliable pushover prediction should lie down within the boundaries defined by the aforementioned perspectives. Thus, an identical approach is here presented with respect to both unstrengthened and strengthened models.

The outcomes from dynamic analyses depend on the applied ground motion record, meaning that it should be properly defined. The source of that record can be either instrumental (recorded from previously occurred earthquakes) or synthetically generated. Each of these methods can induce a level of uncertainty to the obtained outcomes, though this topic is beyond the scope of this study (for details see Watson-Lamprey 2007; Haselton et al. 2009; Wang 2011; Allahvirdizadeh et al. 2013).

Regarding the IDA performed on the models, an artificial generated ground motion record was adopted. The ground motion was generated taking into account the seismicity conditions of Odemira (Alentejo region, southern Portugal) for the near-field earthquake, as established in the Portuguese national annex of Eurocode 8 (IPQ 2010). Simqke-gr software (Simqke_gr 2012), was used to generate a ground motion record compatible with the design spectrum. Subsequently, a baseline correction and a filtering of the frequencies outside of the range $0.1-20 \mathrm{~Hz}$ were performed by means 
570

with the design spectra in Fig. 19. The modes with the highest mass contribution (see Table 2) are also presented in Fig. 19 and reveal the sensitivity of the rammed earth component to earthquakes with high frequencies.

\section{Fig. 19. Generated ground motion record in comparison with the design spectrum (near-field earthquake of Odemira region)}

In addition to the ground motion record, it is vital to define a proper damping ratio of the system to take into account the energy dissipation. In this regard, the Rayleigh viscous damping approach was adopted (Chopra 2012). It should be noted that there is no general consensus about the damping ratio value in rammed earth constructions, particularly when running non-linear dynamic analyses. Hence, a $3 \%$ damping ratio was considered.

The IDA was performed by linearly scaling the generated ground motion a series of times until numerical instability started to be observed. The resulting scaled ground motions were applied to the models in the longitudinal direction ( $\mathrm{X}$ direction in Fig. 3). Then, the hysteretic curves of each analysis, representing the normalized base shear (load factor) as function of the experienced lateral displacement, were used to extract the envelop curves (Fig. 20a). Finally, the points of maximum experienced force and displacements at both positive and negative directions were extracted to plot the force- and displacement-based IDA curves. The resulting IDA curves of the unstrengthened and strengthened models are presented respectively in Fig. $20 \mathrm{~b}$ and c, where they are also compared with the corresponding pushover curve. In general, the pushover analysis seems to accurately predict both the load and displacement capacities of the models with respect to the IDA.

(a)

(c)

Fig. 20. Outcomes of the nonlinear dynamic analyses: (a) example of hysteretic curve envelop (b) displacement- and force-based IDA curves of the plain model (c) displacement- and force-based IDA curves of the strengthened model

Regarding the damage observed in the IDA, Fig. 21 present the contour maps of the maximum values of the principal tensile strains experienced by the models when subjected to the ground motion with the highest intensity. Again, the applied LC-TRM is shown not to change the failure mode, which is composed of shear cracking in the web and detachment of wing walls. Furthermore, the comparison of these contour maps with those presented in Fig. 17 reveal that, in general, the damage predicted by the pushover analyses agrees with that of the nonlinear dynamic analysis. Nevertheless, the damage 
603

604

605

observed in the web wall due to sway of wing walls in the unstrengthened model is not correctly portrayed by pushover.

(a)

Fig. 21. Maximum values of the principal tensile strains of the models observed for the highest intensity ground motion: (a) unstrengthened model (b) strengthened model

\section{Conclusions}

The current study investigated the in-plane seismic performance of rammed earth walls by means of advanced nonlinear finite element modeling. The main remarks are highlighted as follows:

- The conducted sensitivity analyses have shown that parameters other than tensile strength have minor influence on the load and displacement capacities of the numerical models. It was noticed that doubling or halving the tensile strength results in 50\% increase or reduction of the load capacity, respectively.

- Damage (cracking) at both unstrengthened and strengthened models initiates at very low lateral load levels, though due to its local occurrence, the behavior of the wall seems to remain elastic up to higher load levels.

- The comparison between models based on solid elements and those based on shell elements revealed that the latter experience higher lateral displacements due to disregarding of the thickness of the walls. Furthermore, the shell based models were shown to not allow a correct prediction of damage. Thus, the use of solid elements is recommended in the modeling of thick rammed earth walls, like the ones from typical Portuguese dwellings.

- The models with short wing walls achieved higher load and displacement capacities. Moreover, failure due to shear cracking of the web wall is more likely to occur in this component.

- The sections in the unstrengthened model deemed as the most critical are the connections between web and wing walls, despite the observation of some diagonal cracks in the web wall. Thus, detachment of the wing walls is the most likely failure mode of the unstrengthened rammed earth component when subjected to in-plane loading.

- The LC-TRM strengthening increased the loading and displacement capacities of the unstrengthened model in about $21 \%$ and $56 \%$, respectively.

- The LC-TRM strengthening does not change the failure mode of the rammed earth component; nevertheless it postpones failure by assuring a better stress distribution in the critical sections.

- The decrease of the frequency ratio of the highest contributing modes was used as a damage indicator of the pushover analyses and it allowed observing that the LC-TRM strengthening decrease this indicator from $11 \%$ to $6 \%$. 
637 - The comparison of the outcomes of IDA with those of pushover analyses revealed that pushover 638 analysis can reliably predict both the in-plane loading and displacement capacities of the rammed 639 earth models.

640 - The damage evidenced from IDA and pushover analyses portrayed identical failure modes, 641 nevertheless the damage distribution is not properly identical due to the dynamic nature of the 642 loading in the IDA.

643

\section{Acknowledgments}

645 This work was financed by FEDER funds through the Competitively Factors Operational Programme 646 (COMPETE) and by national funds through the Foundation for Science and Technology (FCT) within 647 the scope of projects POCI-01-0145-FEDER-016737 (PTDC/ECM-EST/2777/2014) and POCI-01648 0145-FEDER-007633. The support from grant SFRH/BPD/97082/2013 is also acknowledged.

\section{References}

651 Allahvirdizadeh R, Khanmohammadi M, Marefat MS. Investigating Effects of Scaling and Selecting 652 Earthquakes Ground Motions on Performance-Based Design of RC Buildings. In: $4^{\text {th }}$ International 653 Conference on Concrete and Development, Tehran, Iran; 2013.

654 Allahvirdizadeh R, Khanmohammadi M, Marefat MS. Probabilistic Comparative Investigation on 655 Introduced Performance-Based Seismic Design and Assessment Criteria. Engineering Structures $656 \quad 2017 ; 151: 206-220$.

657 Allahvirdizadeh R. Modelling of the Seismic Behaviour of TRM-Strengthened Rammed Earth Walls. 658 M.Sc. Thesis. University of Minho, Guimarães, Portugal; 2017.

659 Allahvirdizadeh R, Gholipour Y. Reliability Evaluation of Predicted Structural Performances Using 660 Nonlinear Static Analysis. Bulletin of Earthquake Engineering 2017; 15(5): 2129-2148.

661 Allahvirdizadeh R, Oliveira DV, Silva RA. Numerical Modeling of the Seismic Out-of-plane 662 Response of a Plain and TRM-Strengthened Rammed Earth Subassembly, Manuscript submitted for 663 publication; 2018.

664 Ascione L, De Felice G, De Santis S. A Qualification Method for Externally Bonded Fiber Reinforced 665 Cementitious Matrix (FRCM) Strengthening Systems. Composite Part B: Engineering 2015; 78: 497 666506. 
667 Barroso CA. Innovative Seismic Strengthening of Rammed Earth Constructions. M.Sc. Thesis. 668 University of Minho, Guimarães, Portugal; 2017 [In Portuguese].

669 Basili M, Marcari G, Vestroni F. Nonlinear Analysis of Masonry Panels Strengthened With Textile 670 Reinforce Mortar. Engineering Structures 2016; 113: 245-258.

671 Bui QB, Morel JC. Assessing the Anisotropy of Rammed Earth. Construction and Building Materials $672 \quad 2009 ; 23(9): 3005-3011$.

673 Bui QB, Hans S, Morel JC, Do AP. First Exploratory Study on Dynamic Characteristics of Rammed 674 Earth Buildings. Engineering Structures 2011; 33: 3690-3695.

675 Bui TT, Bui QB, Limam A, Morel JC. Modeling Rammed Earth Wall Using Discrete Element 676 Method. Continuum Mechanics and Thermodynamics 2015; 28(1): 523-538.

677 Chopra AK. Dynamic of Structures: Theory and Applications to Earthquake Engineering. Prentice678 Hall Publications; 2012.

679 Ciancio D, Augarde C. Capacity of Unreinforced Rammed Earth Walls Subjected to Lateral Wind 680 Force: Elastic Analysis Versus Ultimate Strength Analysis. Materials and Structures 2013; 46(9): $681 \quad 1569-1585$.

682 Coburn AW, Spence RJS. Earthquake Protection, $2^{\text {nd }}$ Edition. Wiley, Chichester, UK; 2002.

683 Correia MR. Rammed Earth in Alentejo. Argumentum, Lisbon, Portugal; 2007.

684 Correia MR, Varum H, Lourenco PB. Common Damages and Recommendations for the Seismic 685 Retrofitting of Vernacular Dwellings, Seismic Retrofitting: Learning from Vernacular Architecture. 686 Taylor \& Francis Group, London; 2015.

687 De Felice G, De Santis S, Garmendia L, Ghiassi B, Larrinaga P, Lourenco PB, Oliveira DV, Paolacci 688 F, Papanicolaou CG. Mortar-based Systems for Externally Bonded Strengthening of Masonry. 689 Materials and Structures 2014; 47(12): 2021-2037.

690 De Sensi B. Soil, Dissemination of Earth Architecture; 2003 [In Italian].

691 DIANA FEA BV. Displacement Method ANAlyser, Release 10.1. Netherlands; 2017.

692 Dominguez O. Preservation of Rammed Earth Constructions. M.Sc. Thesis. University of Minho, 693 Guimarães, Portugal; 2015.

694 Figueiredo A, Varum H, Costa A, Silveira D, Oliveira C. Seismic Retrofitting Solution of an Adobe 695 Masonry Wall. Materials and Structures 2013; 46(1): 203-219. 
696 Garofano A, Ceroni F, Pecce M. Modeling of the In-plane Behavior of Masonry Walls Strengthened

697 with Polymeric Grids Embedded in Cementitious Mortar Layers. Composite Part B: Engineering 698 2016; 85: 243-258.

699 Gonzalez JRZ. Uniaxial Deformation-Stress Behavior of the Rammed Earth of the Alcazaba Cadima.

700 Materials and Structures 1999; 32(1): 70-74.

701 Haselton CB, et al. Evaluation of Ground Motion Selecting and Modification Methods: Predicting 702 Median Interstory Drift Response of Buildings. PEER Ground Motion Selection and Modification 703 Working Group, Department of Civil Engineering, California State University, Chico, 2009.

704 Houben H, Guillaud H. Earth Constructions - a Comprehensive Guide. CRATerre - EAG, 705 Intermediate Technology Publication, London; 1994.

706 Illampas R, Silva RA, Charmpis RA, Lourenco PB, Ioannou I. Validation of the Repair Effectiveness 707 of Clay-Based Grout Injections by Lateral Load Testing of an Adobe Model Building. Construction 708 and Building Materials 2017; 153: 174-184.

709 IPQ. NP EN 1998-1: Eurocode 8: Design of Structures for Earthquake Resistance - Part 1: General 710 Rules, Seismic Actions and Rules for Buildings. Lisbon: Instituto Português da Qualidade; 2010 [In 711 Portuguese].

712 Jaquin PA, Augarde CE, Gerrard CM. A Chronological Description of the Spatial Development of 713 Rammed Earth Techniques. International Journal of Architectural Heritage 2008; 2(4): 377-400.

714 Librici C. Modeling of the Seismic Performance of a Rammed Earth Building. MSc Thesis. 715 University of Minho, Guimarães, Portugal; 2016.

716 Liley DM, Robinson J. Ultimate Strength of Rammed Earth Walls with Openings. Proceedings of the 717 Institution of Civil Engineers-Structures and Buildings 1995; 110(3): 278-287.

718 Maniatidis V, Walker P, Heath A, Hayward S. Mechanical and Thermal Characteristics of Rammed 719 Earth. In: Proceeding of International Symposium on Earthen Structures, Bangalore, India; 2007.

720 Miccoli L, Müller U, Fontana P. Mechanical Behavior of Earthen Materials: A Comparison Between 721 Earth Block Masonry, Rammed Earth and Cob. Construction and Building Materials 2014; 61: 327722339.

723 Miccoli L, Oliveira DV, Silva RA, Müller U, Schueremans L. Static Behaviour of Rammed Earth: 724 Experimental Testing and Finite Element Modeling. Materials and Structures 2015; 48(10): 34437253456. 
726 Michels J, Widmann R, Czaderski C, Allahvirdizadeh R, Motavalli M. Glass Transition Evaluation of 727 Commercially Available Epoxy Resins Used for Civil Engineering Applications. Composite Part B: 728 Engineering 2015; 77:484-493.

729 Mininno G, Ghiassi B, Oliveira DV. Modeling of the In-plane and Out-of-plane Performance of 730 TRM-Strengthened Masonry Walls. Key Engineering Materials 2017; 747:60-68.

731 Minke G. Building with Earth-Design and Technology of a Sustainable Architecture. Birkhãuser732 Publisher for Architecture; 2006.

733 Mordanova A, De Santis S, De Felice G. State-of-the-art Review of Out-of-plane Strengthening of 734 Masonry Walls with Mortar-based Composites. In: Proceedings of $10^{\text {th }}$ International Conference on 735 Structural Analysis of Historical Constructions: Anamnesis, Diagnosis, Therapy, Controls (SAHC), 736 Leuven, Belgium; 2016.

737 Oliveira DV, Silva RA, Barroso CA, Lourenco PB. Characterization of a Compatible Low Cost 738 Strengthening Solution Based on the TRM Technique for Rammed Earth. Key Engineering Materials 739 2017; 747: 150-157.

740 Papanicolaou CG, Triantafillou TC, Kyriakos K, Papathanasiou M. Textile Reinforced Mortar (TRM) 741 versus FRP as Strengthening Material of URM Walls: In-plane Cyclic Loading. Materials and 742 Structures 2007; 40(10): 1081-1097.

743 Papanicolaou CG, Triantafillou TC, Papathanasiou M, Kyriakos K. Textile Reinforced Mortar (TRM) 744 versus FRP as Strengthening Material of URM Walls: Out-of-plane Cyclic Loading. Materials and 745 Structures 2008; 41(1): 143-157.

746 Parreira DJ. Seismic Analysis of a Rammed Earth Building. MSc Thesis. Instituto Superior Técnico, 747 Lisbon, Portugal; 2007 [In Portuguese].

748 Sadeghi NH, Oliveira DV, Silva RA, Mendes N, Correia M, Azizi-Bonsarabadi. Performance of 749 Adobe Vaults Strengthened with LC-TRM: An Experimental Approach. In: $3^{\text {rd }}$ International 750 Conference on Protection of Historical Constructions (Prohitech), Lisbon, Portugal; 2017.

751 Seismosoft, 2016. SeismoSignal - A Computer Program for Signal Processing of Time-Histories. 752 Available at URL: www.seismosoft.com.

753 Silva RA. Repair of Earth Constructions by Means of Grout Injection. PhD Dissertation. University of 754 Minho, Guimarães, Portugal; 2013.

755 Silva RA, Oliveira DV, Schueremans L, Lourenco PB, Miranda T. Modelling the Structural 756 Behaviour of Rammed Earth Components. In: $12^{\text {th }}$ International Conference on Computational 757 Structures Technology, Stirlingshire, Scotland; 2014. 
Silva RA, Oliveira DV, Schueremans L, Miranda T, Machado J. Effectiveness of the Repair of Unstabilised Rammed Earth with Injection of Mud Grouts. Construction and Building Materials 2016; 127: 861-871.

Silva RA, Dominguez-Martinez O, Oliveira DV, Pereira EB. Comparison of the Performance of Hydraulic Lime- and Clay-Based Grouts in the Repair of Rammed Earth. Construction and Building Materials 2018a; 193: 384-394.

Silva RA, Mendes N, Oliveira DV, Romanazzi A, Dominguez-Martinez O, Miranda T. Evaluating the Seismic Behaviour of Rammed Earth Buildings from Portugal: From Simple Tools to Advanced Approaches. Engineering Structures 2018b; 157: 144-156.

Simqke_gr, 2012. Program for Generating Spectrum-Compatible Artificial Accelerograms. Available at URL: http://gelfi.unibs.it/software/simqke/simqke_gr.htm.

Valluzzi MR, Modena C, De Felice G. Current Practice and Open Issues in Strengthening Historical Buildings with Composites. Materials and Structures 2014; 47(12): 1971-1985.

Vamvatsikos D, Cornell CA. Incremental Dynamic Analysis. Earthquake Engineering \& Structural Dynamics 2002; 31(3): 491-514.

Wang G. A Ground Motion Selection and Modification Method Capturing Response Spectrum Characteristics and Variability of Scenario Earthquakes. Soil Dynamics and Earthquake Engineering 2011; 31(4): 611-625.

Wang Y, Wang M, Liu K, Pan W, Yang X. Shaking Table Tests on Seismic Retrofitting of Rammed Earth Structures. Bulletin of Earthquake Engineering 2016; 15(3): 1037-1055.

Watson-Lamprey JA. Selection and Scaling of Ground Motion Time-Series. PhD Thesis. University of California, Berkeley, USA; 2007.

Yamin LE, Philips CA, Reyes JC, Ruiz DM. Seismic Behavior and Rehabilitation Alternatives for Adobe and Rammed Earth Buildings. In: Proceedings of $13^{\text {th }}$ World Conference on Earthquake

\section{Engineering, Vancouver, B.C., Canada; 2004.}


Fig. 1. Rammed earth constructions in Portugal: (a) Alentejo region (in red); (b) examples of typical dwellings (Silva et al. 2018b)

Fig. 2. Average length and height of the rammed earth walls identified in the surveyed rammed earth dwellings

Fig. 3. Considered in-plane models: (a) $50 \mathrm{~cm}$ long wing walls (b) $80 \mathrm{~cm}$ long wing walls

Fig. 4. Detailed view of the materials and interaction levels contributing for the structural behavior of the unstrengthened and strengthened models

Fig. 5. Adopted compressive behavior of the rammed earth material

Fig. 6. Adopted stress-strain behavior of the LC-TRM strengthening

Fig. 7. Schematic view of the shell models

Fig. 8. Types of elements employed in the preparation of the models: (a) CHX60 (b) CQ40S (c) CQ48I (DIANA FEA BV 2017)

Fig. 9. Frequency ratios between the shell and solid models for the six first corresponding modes

Fig. 10. Pushover curves obtained from the sensitivity analyses of the unstrengthened solid model with $50 \mathrm{~cm}$ wing walls: (a) Compressive strength (b) Poisson's ratio (c) Young modulus (d) Tensile strength (e) Tensile fracture energy

Fig. 11. Pushover curves of the unstrengthened models: (a) Shell model with $80 \mathrm{~cm}$ wings (b) Solid model with $80 \mathrm{~cm}$ wings (c) Shell model with $50 \mathrm{~cm}$ wings (d) Solid model with $50 \mathrm{~cm}$ wings

Fig. 12. Total lateral displacements at the peak capacity of the unstrengthened models: (a) shell model with $80 \mathrm{~cm}$ long wings (b) solid model with $80 \mathrm{~cm}$ long wings (c) shell model with $50 \mathrm{~cm}$ long wings (d) solid model with $50 \mathrm{~cm}$ long wings

Fig. 13. Principal tensile strains at the peak capacity of the unstrengthened models: (a) shell model with $80 \mathrm{~cm}$ long wings (b) solid model with $80 \mathrm{~cm}$ long wings (c) shell model with $50 \mathrm{~cm}$ long wings (d) solid model with $50 \mathrm{~cm}$ long wings

Fig. 14. Influence of wing walls on performance of the rammed earth component: (a) pushover curve (b) principal tensile strains of the unstrengthened rammed earth wall with $50 \mathrm{~cm}$ long wing walls (c) principal tensile strains of the unstrengthened rammed earth wall without wing walls

Fig. 15. Pushover curves of the strengthened model

Fig. 16. Total lateral displacements of the strengthened model in comparison to the plain one: (a) unstrengthened model at its peak capacity (b) strengthened model at the peak capacity of the unstrengthened model (c) strengthened model at its peak capacity

Fig. 17. Principal tensile strains of the strengthened model in comparison to the unstrengthened one: (a) unstrengthened model at its peak capacity (b) strengthened model at the peak capacity of the unstrengthened 
820 model (c) strengthened model at its peak capacity (d) LC-TRM strengthening at peak capacity of the 821 strengthened model

822 Fig. 18. Damage evolution based on the frequency ratio of the highest participating modes: (a) Mode 1 (b) 823 Mode 4 (c) Mode 8 (d) Mode 10

824 Fig. 19. Generated ground motion record in comparison with the design spectrum (near-field earthquake of 825 Odemira region)

826 Fig. 20. Outcomes of the nonlinear dynamic analyses: (a) example of hysteretic curve envelop (b) displacement827 and force-based IDA curves of the plain model (c) displacement- and force-based IDA curves of the 828 strengthened model

829 Fig. 21. Maximum values of the principal tensile strains of the models observed for the highest intensity ground motion: (a) unstrengthened model (b) strengthened model 
This paper can be found at https://doi.org/10.1080/15583058.2019.1629507

850 Table 1. Parameters considered in the sensitivity analysis

851 Table 2. Initial (undamaged) dynamic properties of the unstrengthened and strengthened models 852

853

854

855

856

857

858

859

860

861

862

863

864

865

866

867

868

869

870

871

872

873

874

875 


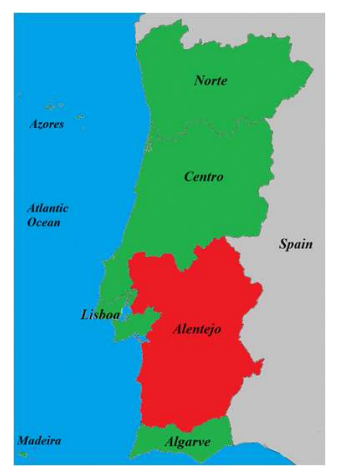

(a)

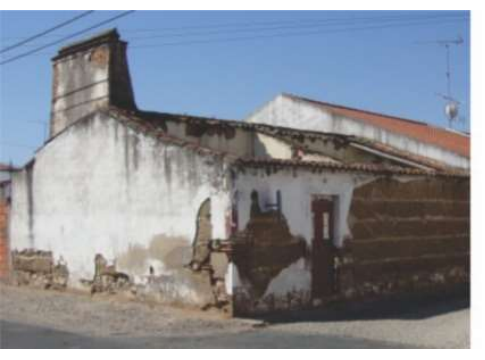

(b)

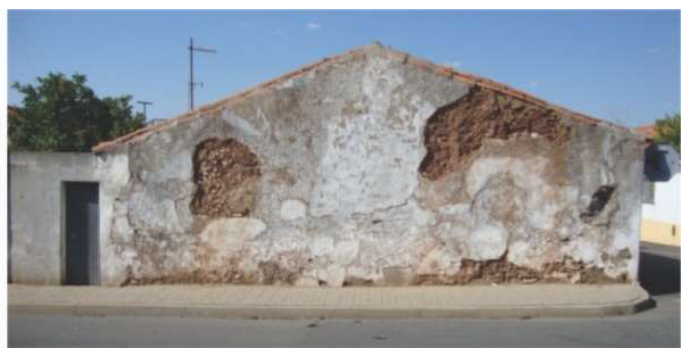

876 Fig. 1. Rammed earth constructions in Portugal: (a) Alentejo region (in red); (b) examples of typical dwellings 


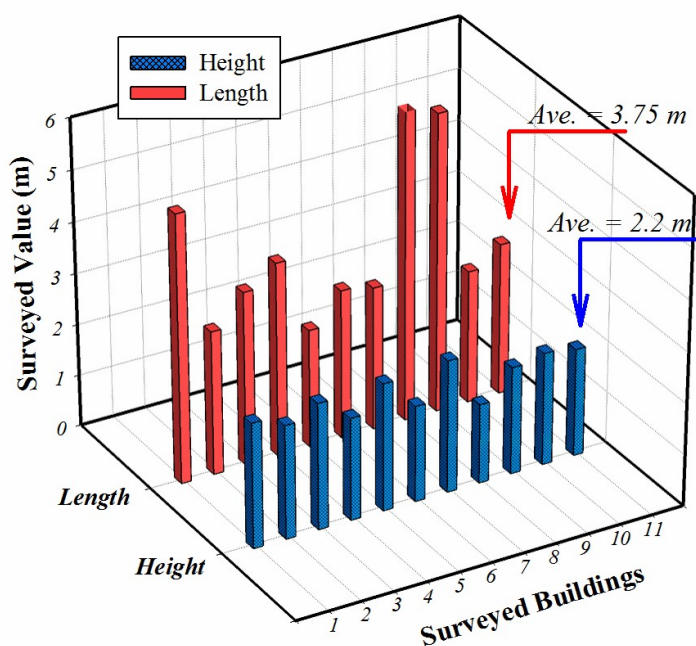

Fig. 2. Average length and height of the rammed earth walls identified in the surveyed rammed earth dwellings 892

893

894

895

896

897

898

899

900

901

902

903

904 
This paper can be found at https://doi.org/10.1080/15583058.2019.1629507

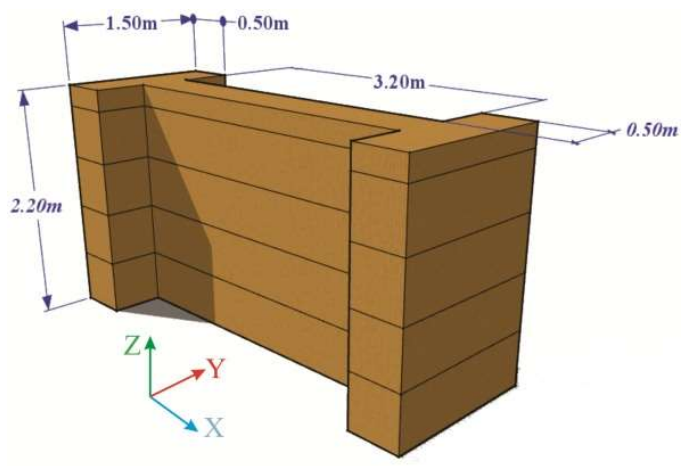

(a)

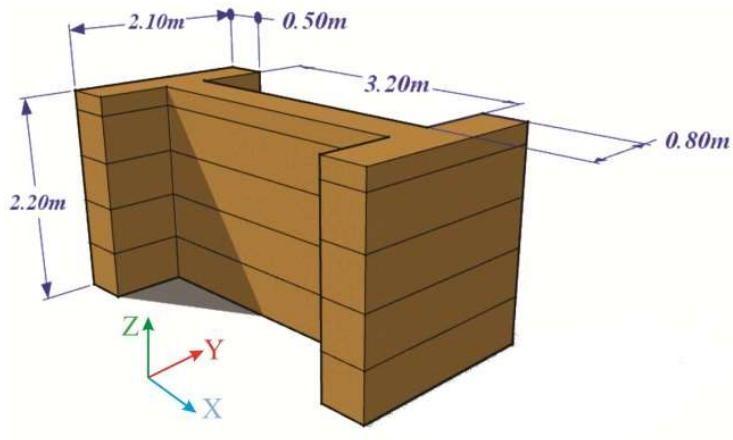

(b)

Fig. 3. Considered in-plane models: (a) $50 \mathrm{~cm}$ long wing walls (b) $80 \mathrm{~cm}$ long wing walls

906

907

908

909

910

911

912

913

914

915

916

917

918

919

920

921

922 


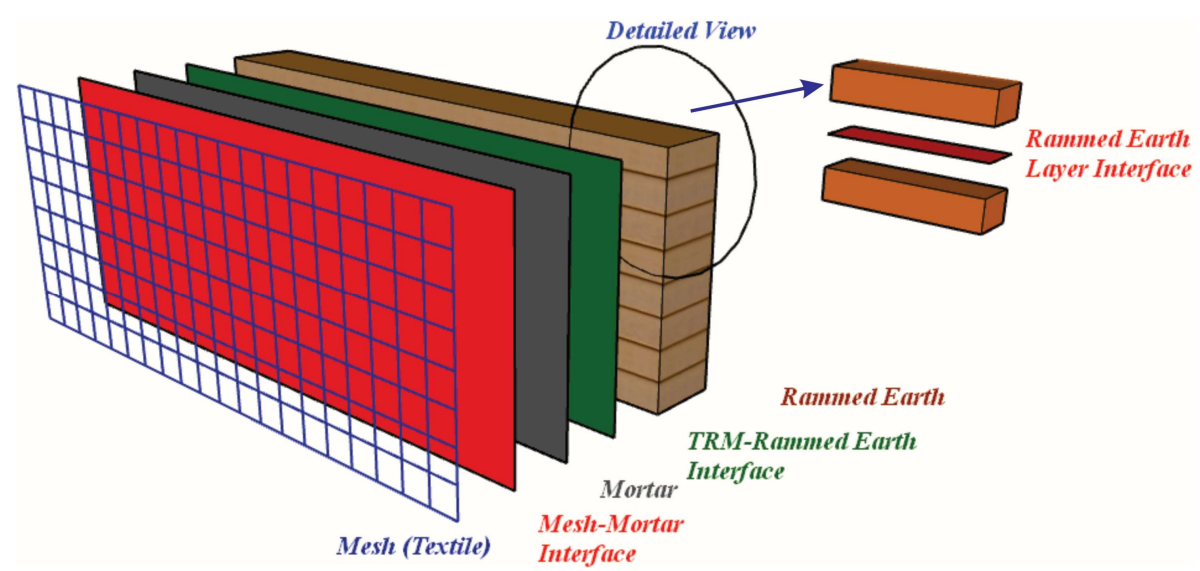

Fig. 4. Detailed view of the materials and interaction levels contributing for the structural behavior of the unstrengthened and strengthened models

926

927

928

929

930

931

932

933

934

935

936

937

938 
This paper can be found at https://doi.org/10.1080/15583058.2019.1629507

939

941

942

943

944

945

946

947

948

949

950

951

952

953

954

955

956

957

958

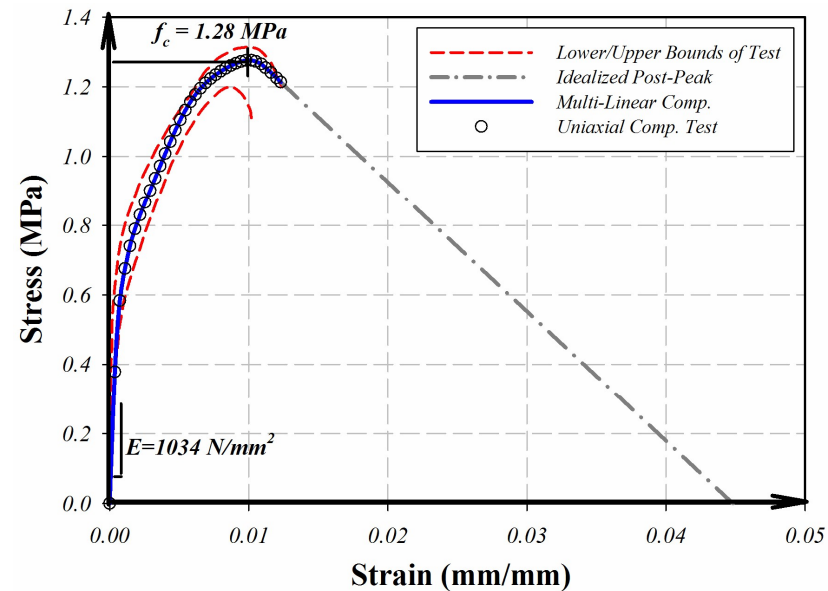

Fig. 5. Adopted compressive behavior of the rammed earth material 


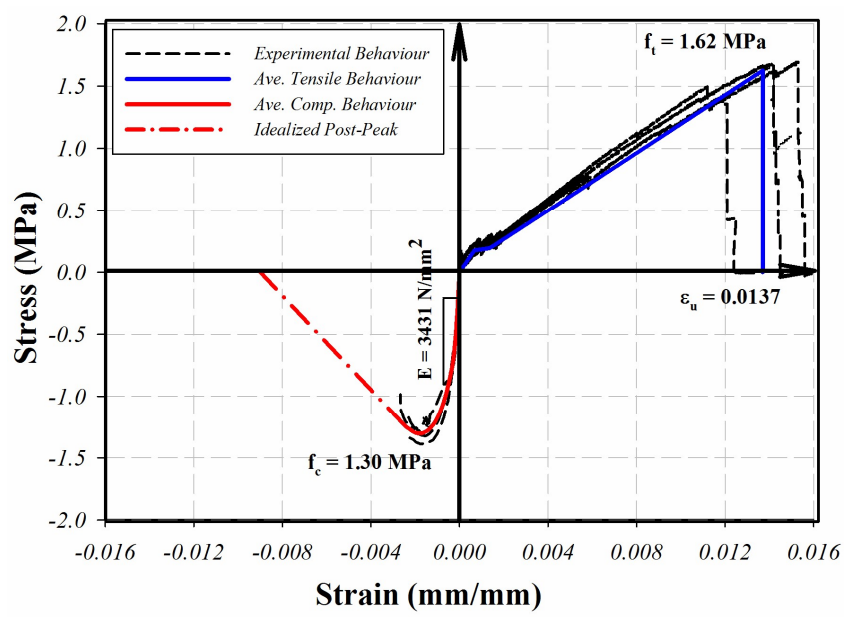


This paper can be found at https://doi.org/10.1080/15583058.2019.1629507

976

977

978

979

980

981

982

983

984

985

986

987

988

989

990

991

992

993

994

995

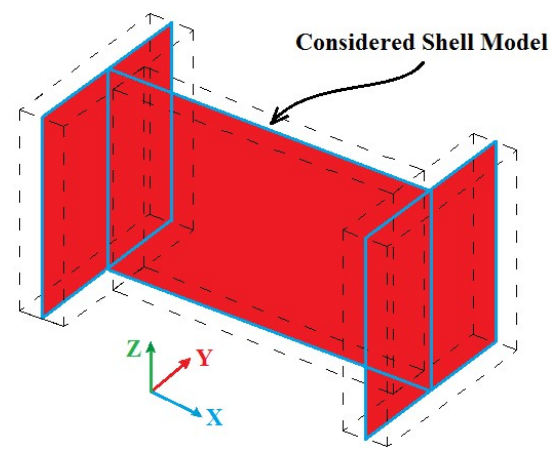

Fig. 7. Schematic view of the shell models 


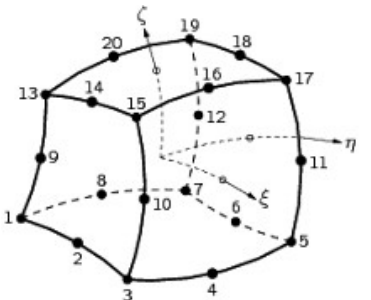

(a)

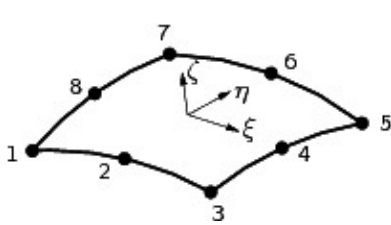

(b)

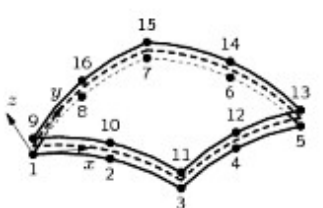

(c)

996

997

998

999

1000

1001

1002

1003

1004

1005

1006

1007

1008

1009

1010

1011

1012
Fig. 8. Types of elements employed in the preparation of the models: (a) CHX60 (b) CQ40S (c) CQ48I

(DIANA FEA BV 2017)

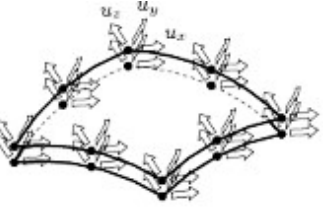


This paper can be found at https://doi.org/10.1080/15583058.2019.1629507

1013

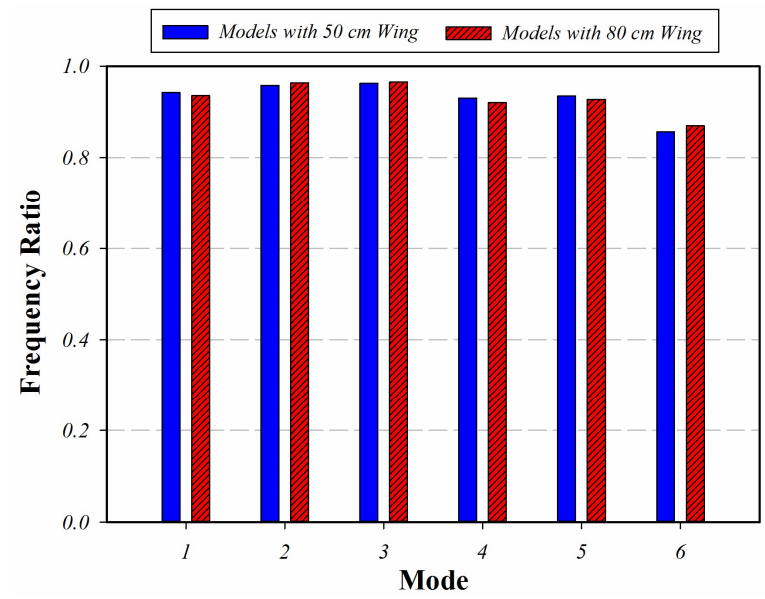

1014

Fig. 9. Frequency ratios between the shell and solid models for the six first corresponding modes

1015

1016

1017

1018

1019

1020

1021

1022

1023

1024

1025

1026

1027

1028

1029 


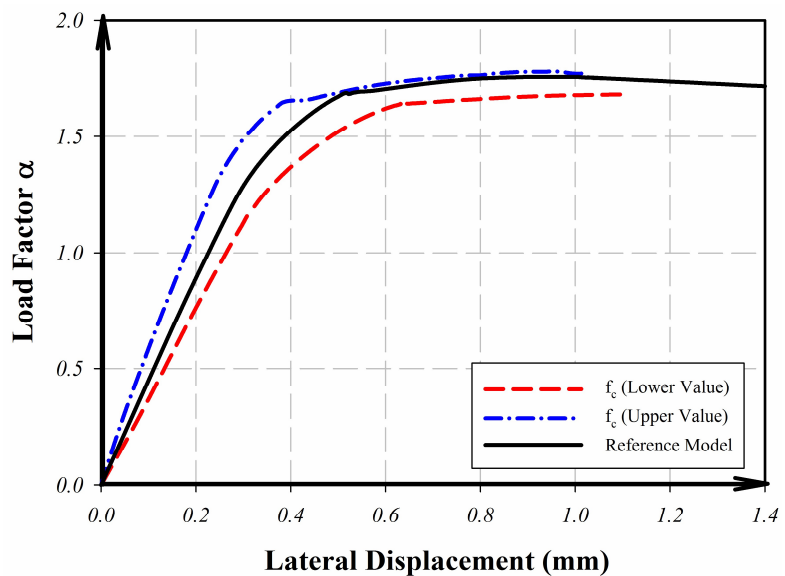

(a)

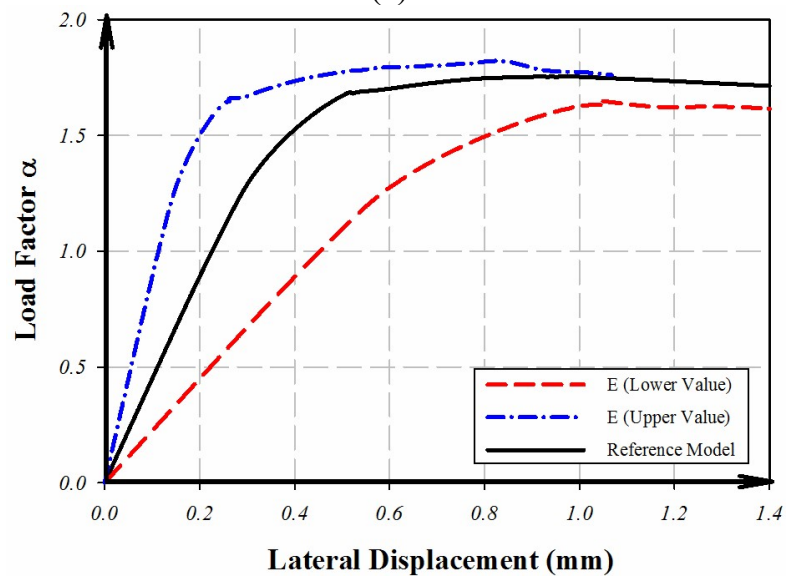

(c)

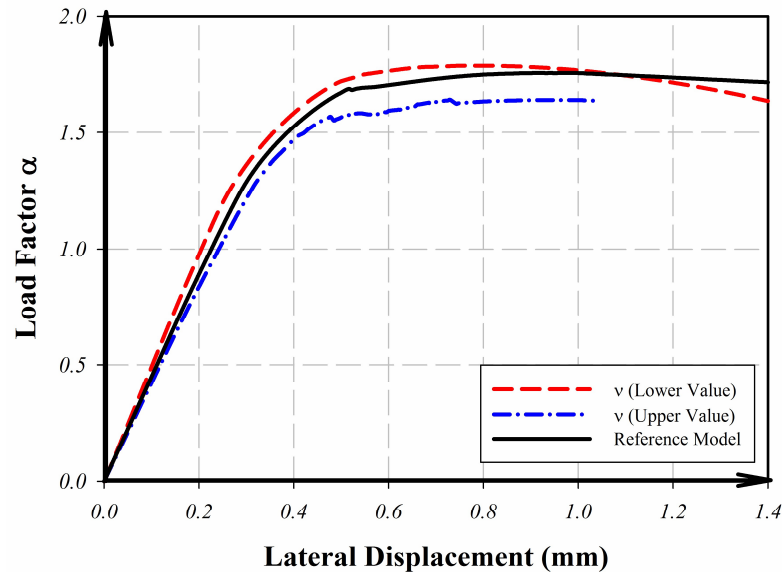

(b)

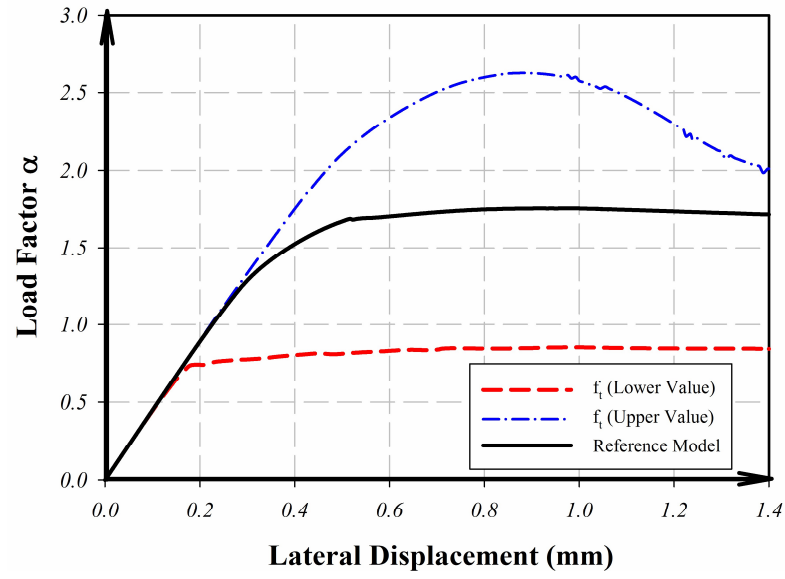

(d)

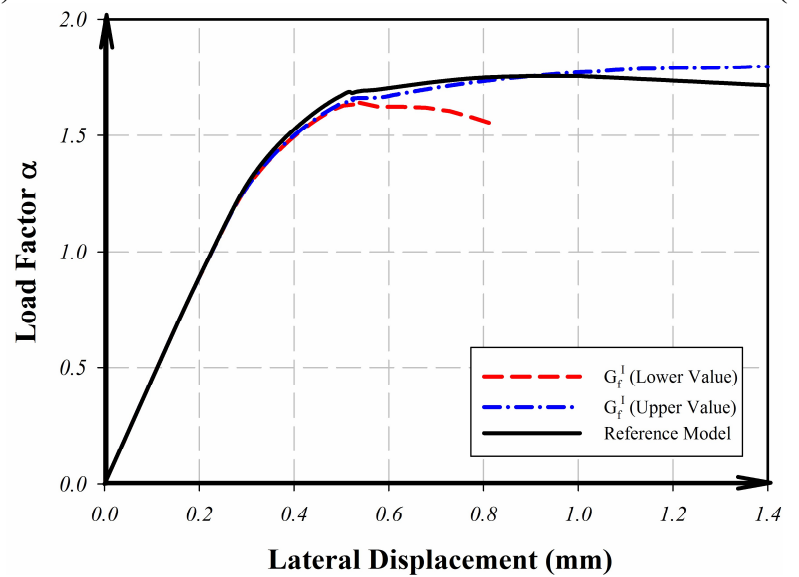

(e)

Fig. 10. Pushover curves obtained from the sensitivity analyses of the unstrengthened solid model with $50 \mathrm{~cm}$ wing walls: (a) Compressive strength (b) Poisson's ratio (c) Young modulus (d) Tensile strength (e) Tensile fracture energy 


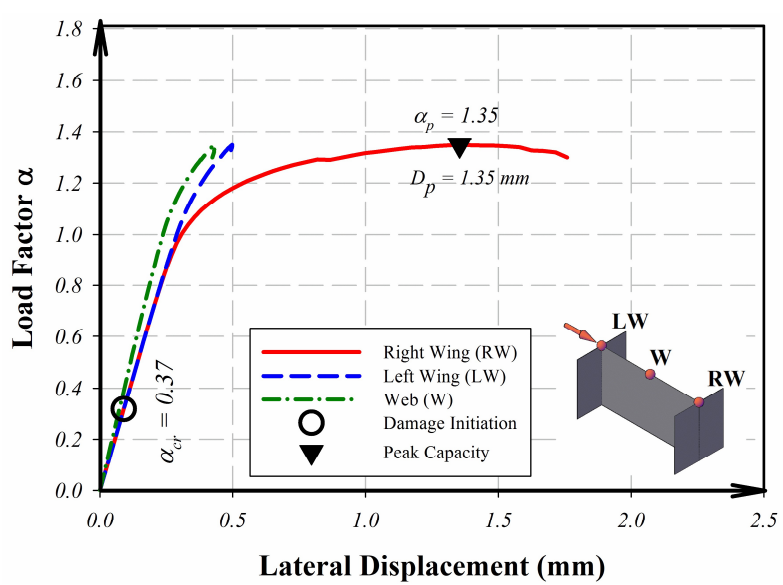

(a)

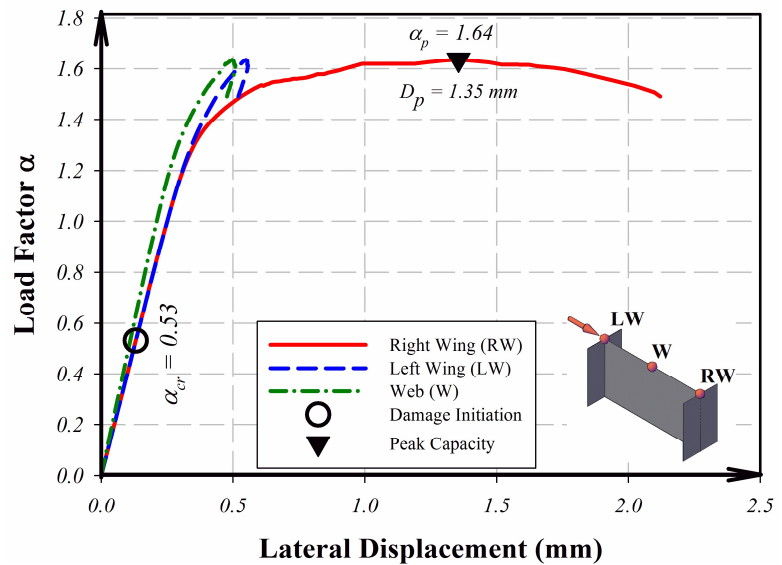

(c)

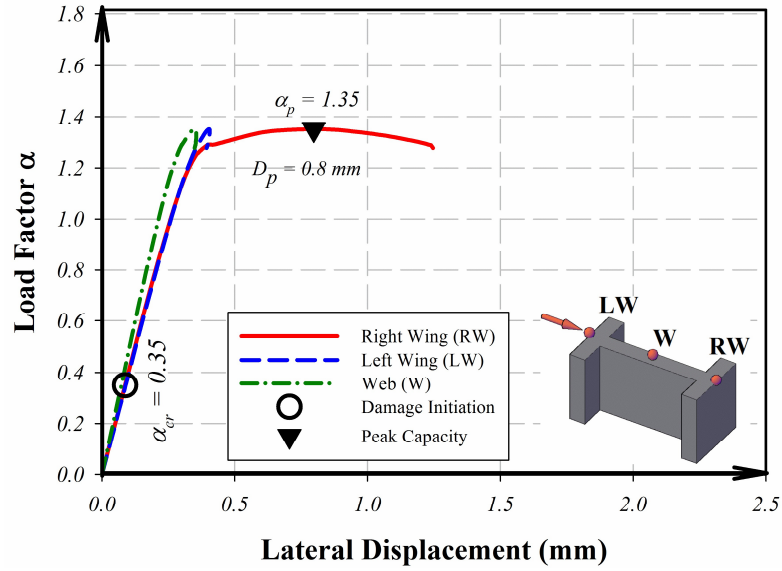

(b)

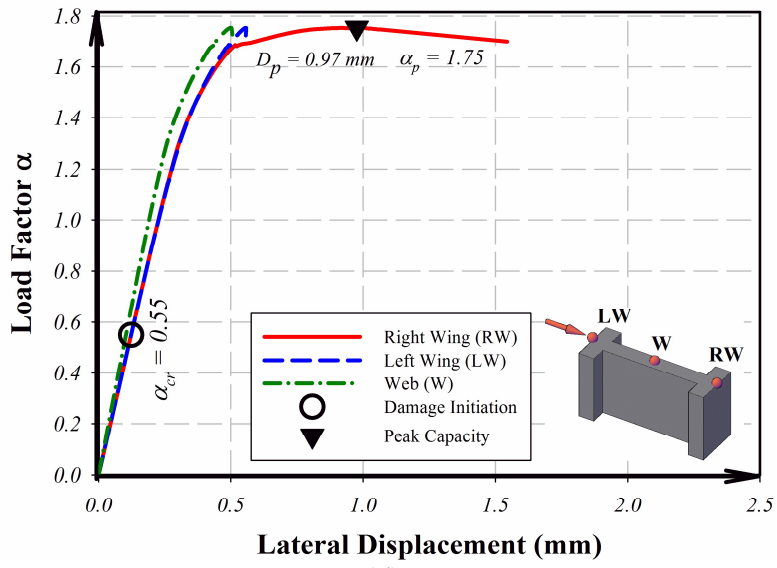

(d)
1038

1042

1043

1044

1045

1046

1047

1048

1049

Fig. 11. Pushover curves of the unstrengthened models: (a) Shell model with $80 \mathrm{~cm}$ wings (b) Solid model with $80 \mathrm{~cm}$ wings (c) Shell model with $50 \mathrm{~cm}$ wings (d) Solid model with $50 \mathrm{~cm}$ wings 
1051

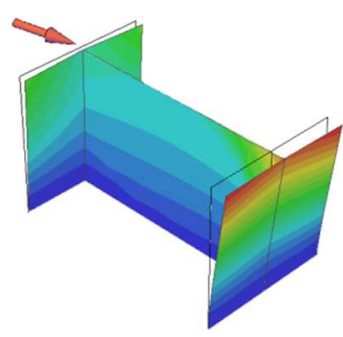

(a)

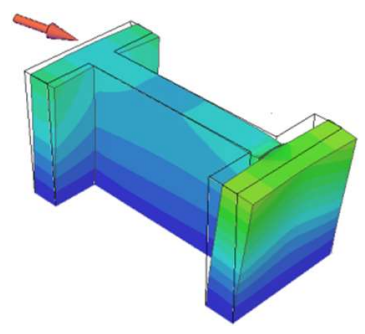

(b)

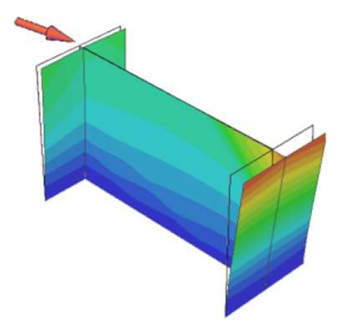

(c)

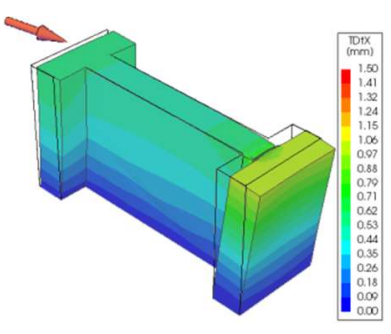

(d)

1052 Fig. 12. Total lateral displacements at the peak capacity of the unstrengthened models: (a) shell model with

1053

1054 $80 \mathrm{~cm}$ long wings (b) solid model with $80 \mathrm{~cm}$ long wings (c) shell model with $50 \mathrm{~cm}$ long wings (d) solid model with $50 \mathrm{~cm}$ long wings

1055

1056

1057

1058

1059

1060

1061

1062

1063

1064

1065

1066

1067

1068

1069

1070

1071 
This paper can be found at https://doi.org/10.1080/15583058.2019.1629507

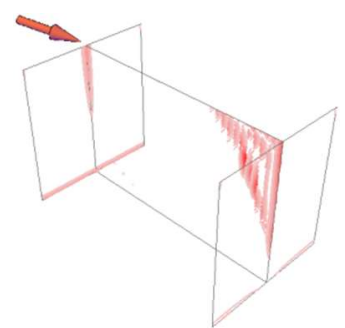

(a)

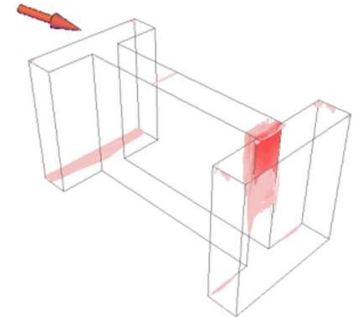

(b)

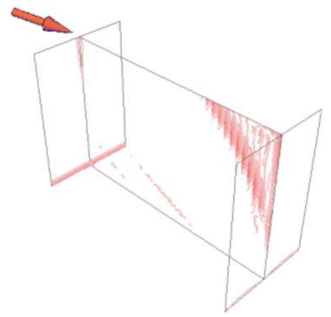

(c)

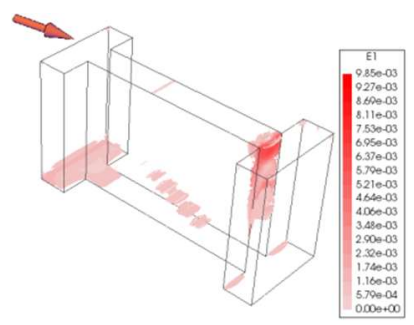

(d)

1072 Fig. 13. Principal tensile strains at the peak capacity of the unstrengthened models: (a) shell model with $80 \mathrm{~cm}$ long wings (b) solid model with $80 \mathrm{~cm}$ long wings (c) shell model with $50 \mathrm{~cm}$ long wings (d) solid model with

1076

1077

1078

1079

1080

1081

1082

1083

1084

1085

1086

1087

1088

1089 


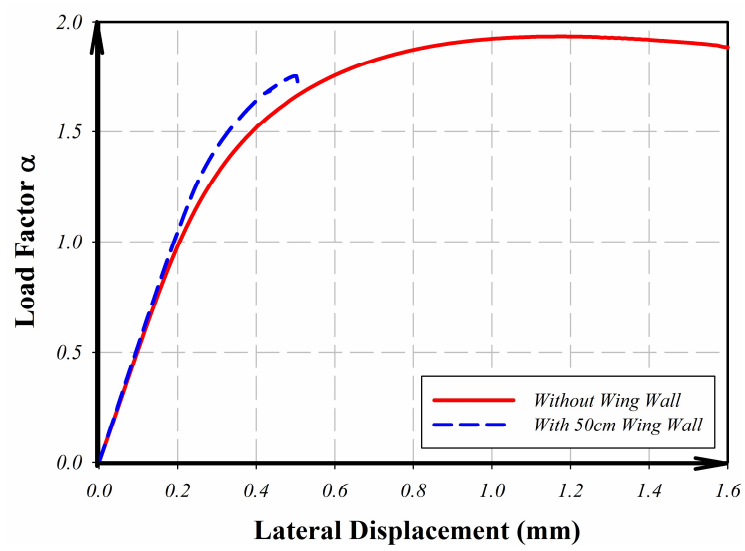

(a)

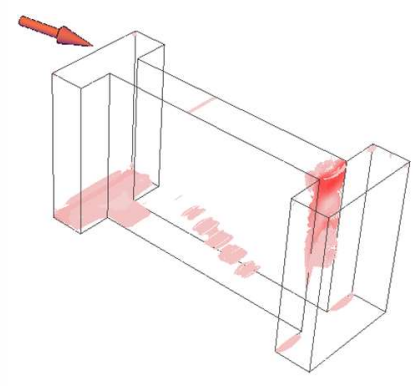

(b)

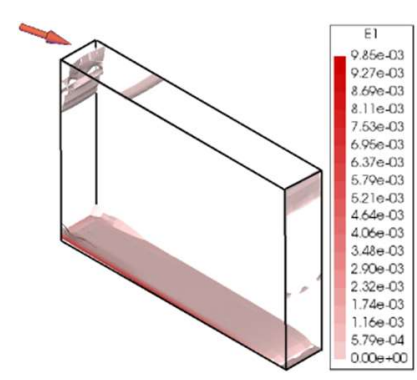

(c)
1090

1091

1092

1093

1094

1095

1096

1097

1098

1099

1100

1101

1102

1103

1104

1105

1106

1107

1108

1109

1110

Fig. 14. Influence of wing walls on performance of the rammed earth component: (a) pushover curve (b) principal tensile strains of the unstrengthened rammed earth wall with $50 \mathrm{~cm}$ long wing walls (c) principal tensile strains of the unstrengthened rammed earth wall without wing walls 
This paper can be found at https://doi.org/10.1080/15583058.2019.1629507

1111

1112

1113

1114

1115

1116

1117

1118

1119

1120

1121

1122

1123

1124

1125

1126

1127

1128

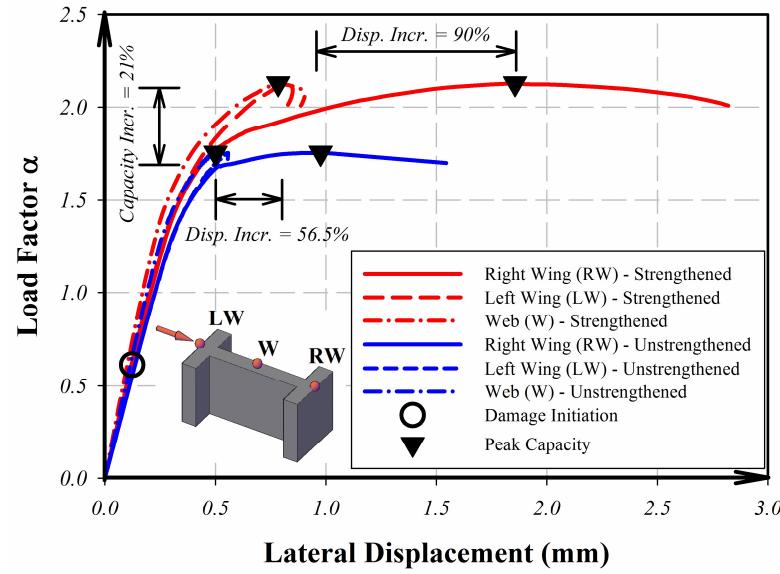

Fig. 15. Pushover curves of the strengthened model 


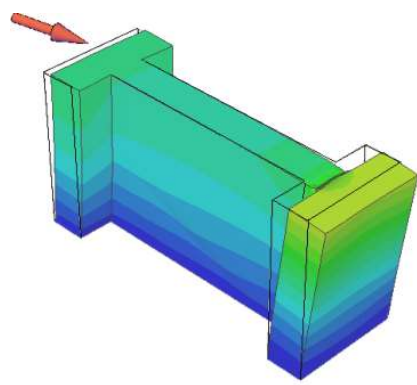

(a)

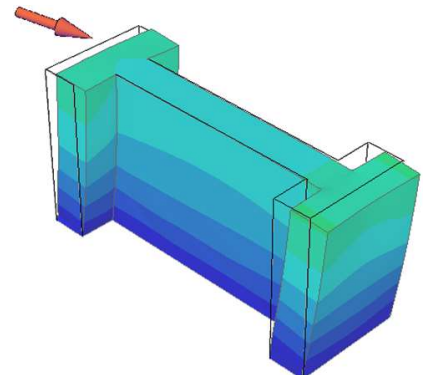

(b)

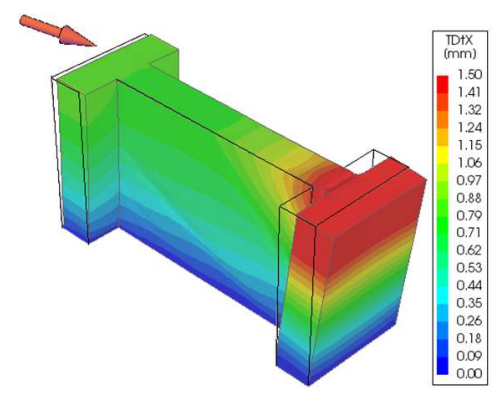

(c)
1132

1133

1134

1135

1136

1137

1138

1139

1140

1141

1142

1143

1144

1145

1146

1147

1148

Fig. 16. Total lateral displacements of the strengthened model in comparison to the plain one: (a) model (c) strengthened model at its peak capacity

(1)

6

\begin{abstract}
unstrengthened model at its peak capacity (b) strengthened model at the peak capacity of the unstrengthened
\end{abstract}




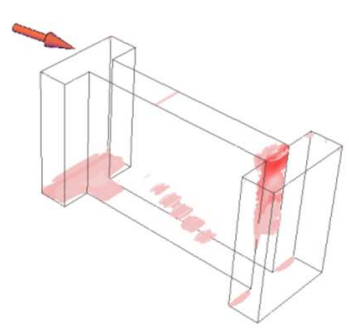

(a)

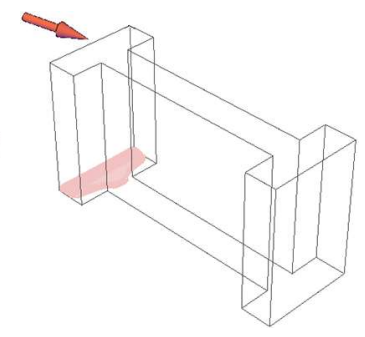

(b)

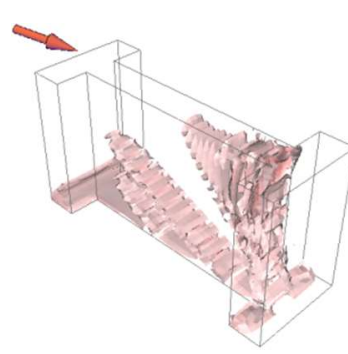

(c)

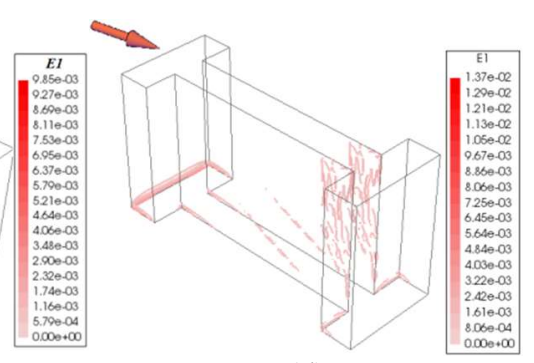

(d)

1149 Fig. 17. Principal tensile strains of the strengthened model in comparison to the unstrengthened one: (a)

1150 unstrengthened model at its peak capacity (b) strengthened model at the peak capacity of the unstrengthened model (c) strengthened model at its peak capacity (d) LC-TRM strengthening at peak capacity of the 


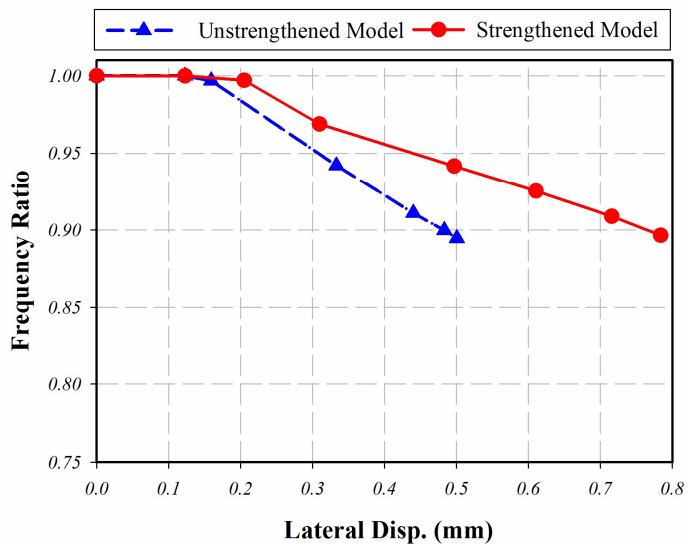

(a)

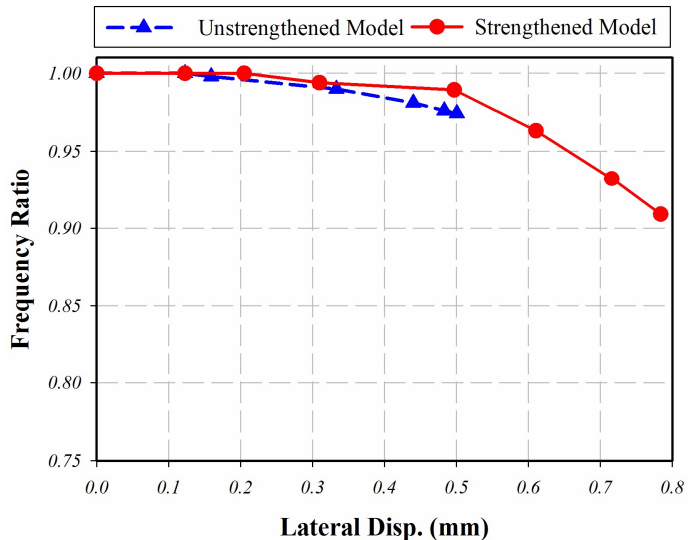

(c)

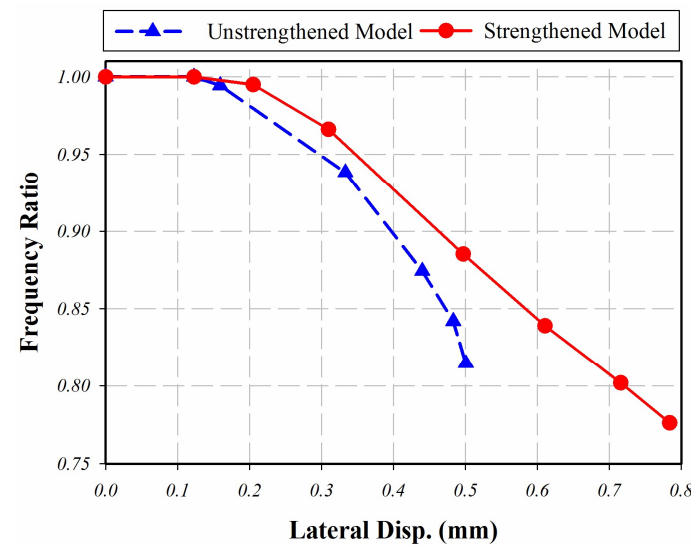

(b)

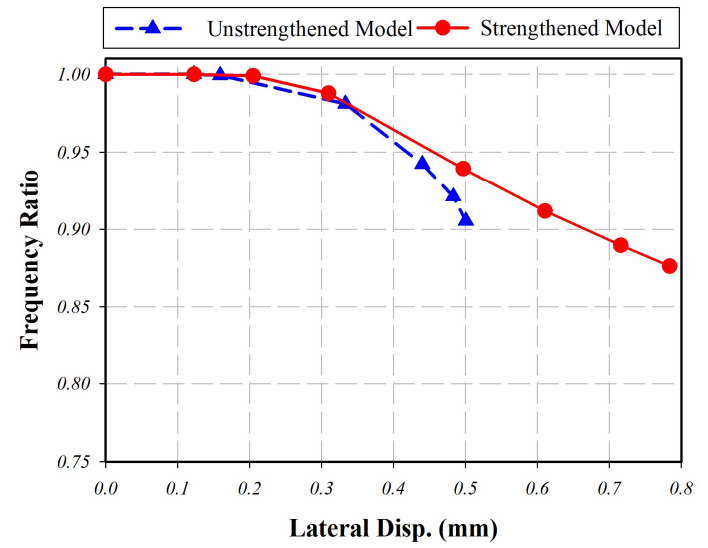

(d)

Fig. 18. Damage evolution based on the frequency ratio of the highest participating modes: (a) Mode 1 (b) 
This paper can be found at https://doi.org/10.1080/15583058.2019.1629507

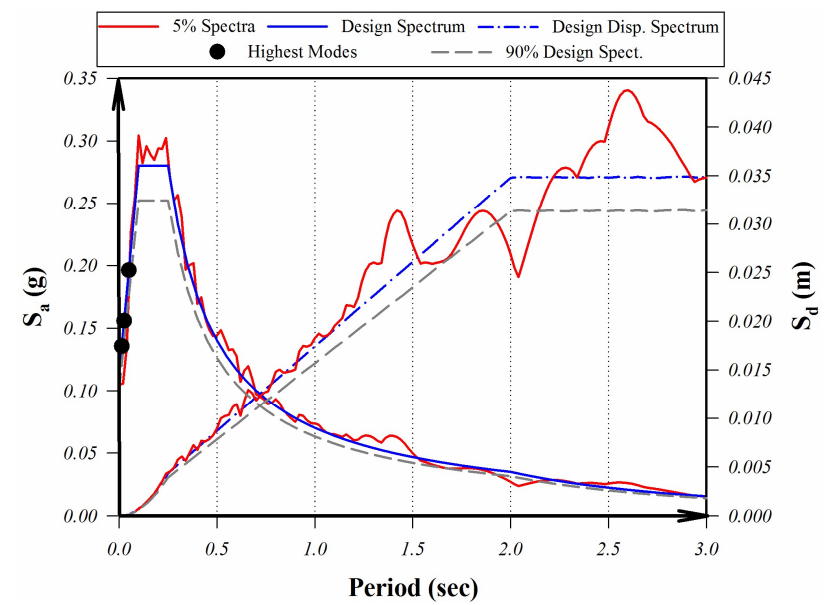

1183

Fig. 19. Generated ground motion record in comparison with the design spectrum (near-field earthquake of

1186

1187

1188

1189

1190

1191

1192

1193

1194

1195

1196

1197

1198

1199

1200

1201

1202

1203

1204 


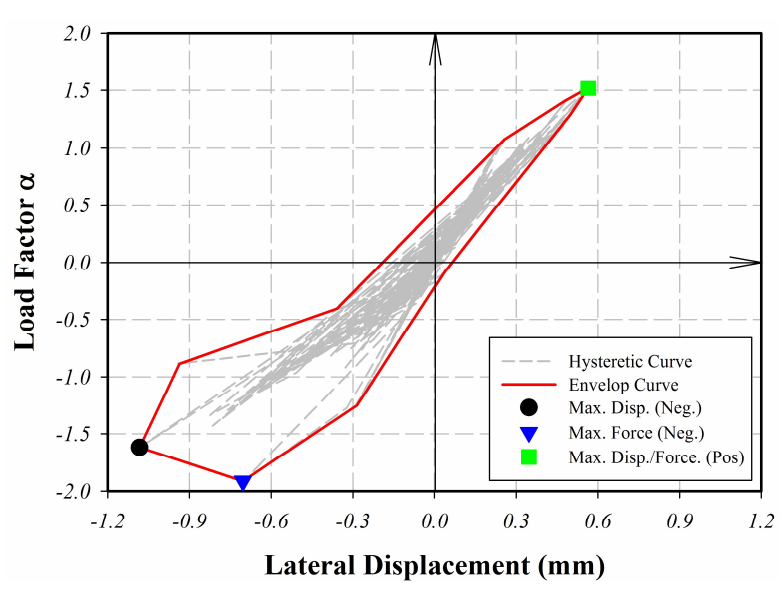

(a)

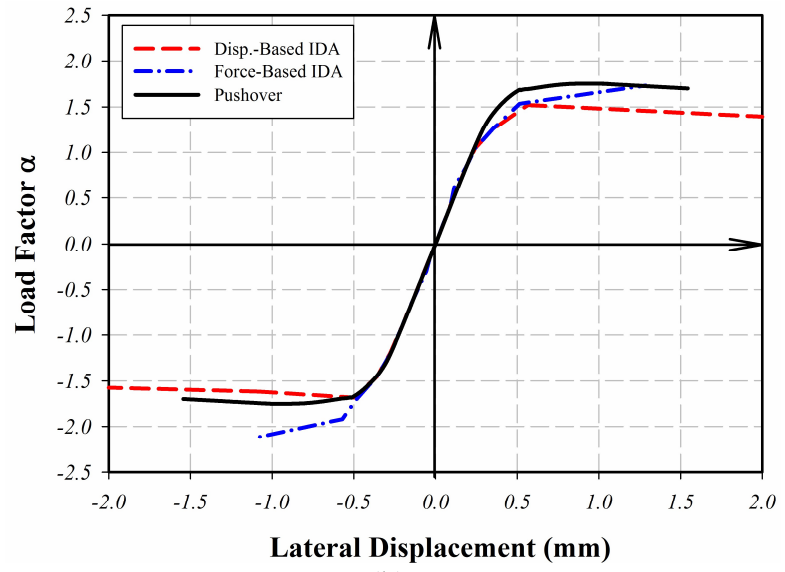

(b)

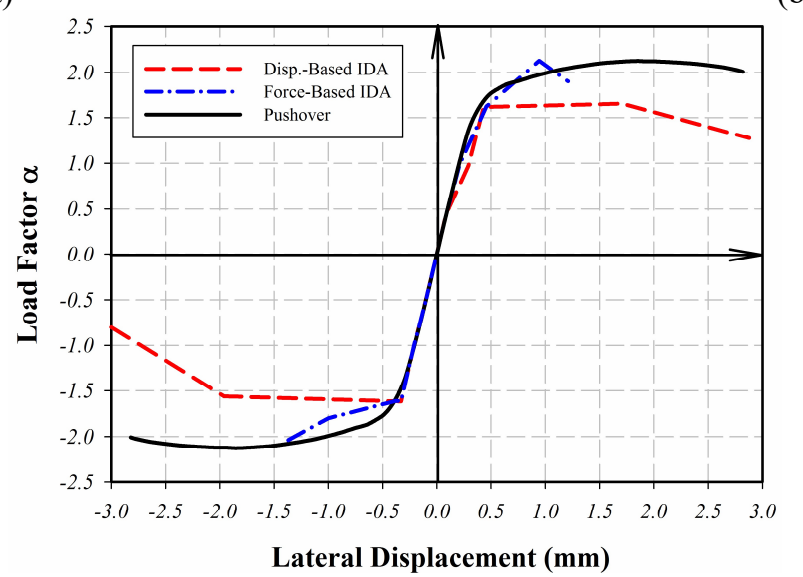

(c)

Fig. 20. Outcomes of the nonlinear dynamic analyses: (a) example of hysteretic curve envelop (b) displacementand force-based IDA curves of the plain model (c) displacement- and force-based IDA curves of the 


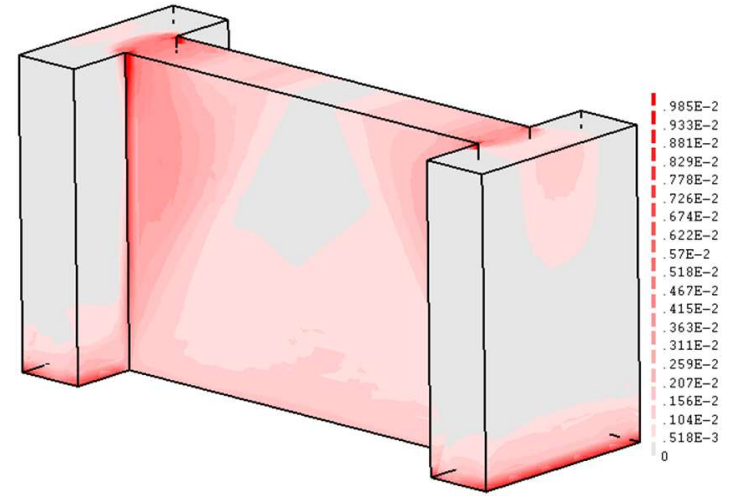

(a)

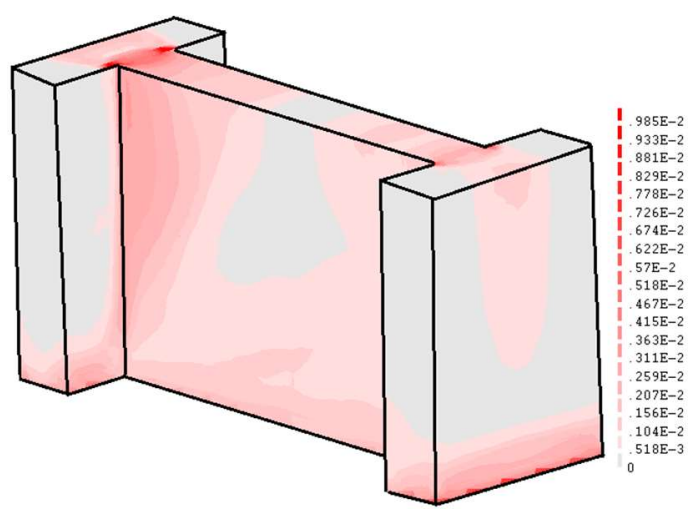

(b)
1220

1224

1225

1226

1227

1228

1229

1230

1231

1232

1233

1234

1235

1236

1237

1238

1239

1240

1241 motion: (a) unstrengthened model (b) strengthened model

Fig. 21. Maximum values of the principal tensile strains of the models observed for the highest intensity ground 
This paper can be found at https://doi.org/10.1080/15583058.2019.1629507

1242

Table 1. Parameters considered in the sensitivity analysis

\begin{tabular}{cccc}
\hline \hline Parameter & Reference Value & Lower Value & Upper Value \\
\hline \hline Compressive Strength & $f_{c}=1.28 \mathrm{MPa}$ & $0.5 f_{c}=0.64 \mathrm{MPa}$ & $2.0 f_{c}=2.56 \mathrm{MPa}$ \\
Poisson's Ratio & $v_{r e f}=0.27$ & $v_{\text {lower }}=0.1$ & $v_{\text {upepr }}=0.4$ \\
Young Modulus & $E=1034 \mathrm{MPa}$ & $0.5 E=517 \mathrm{MPa}$ & $2.0 E=2068 \mathrm{MPa}$ \\
Tensile Strength & $f_{t}=0.05 \mathrm{MPa}$ & $0.5 f_{t}=0.025 \mathrm{MPa}$ & $2.0 f_{t}=0.1 \mathrm{MPa}$ \\
Tensile Fracture Energy & $G_{f}^{I}=0.074 \mathrm{~N} / \mathrm{mm}$ & $0.5 G_{f}^{I}=0.037 \mathrm{~N} / \mathrm{mm}$ & $2.0 G_{f}^{I}=0.148 \mathrm{~N} / \mathrm{mm}$ \\
\hline \hline
\end{tabular}

1243

1244

1245

1246

1247

1248

1249

1250

1251

1252

1253

1254

1255

1256

1257

1258

1259

1260

1261

1262

1263

1264 
This paper can be found at https://doi.org/10.1080/15583058.2019.1629507

Table 2. Initial (undamaged) dynamic properties of the unstrengthened and strengthened models

\begin{tabular}{|c|c|c|c|}
\hline Mode & Mode Shape & $\begin{array}{c}\text { Unstrengthened } \\
\text { Model }\end{array}$ & $\begin{array}{c}\text { Strengthened } \\
\text { Model }\end{array}$ \\
\hline \multirow{3}{*}{1} & & $f_{l}=19.9 \mathrm{~Hz}$ & $f_{l}=22.1 \mathrm{~Hz}$ \\
\hline & & $C E M_{x}=0.0 \%$ & $C E M_{x}=0.0 \%$ \\
\hline & & $C E M_{y}=55.8 \%$ & $C E M_{y}=57.5 \%$ \\
\hline \multirow{3}{*}{4} & & $f_{4}=38.3 \mathrm{~Hz}$ & $f_{4}=40.3 \mathrm{~Hz}$ \\
\hline & & $C E M_{x}=72.2 \%$ & $C E M_{x}=72.3 \%$ \\
\hline & & $C E M_{y}=62.5 \%$ & $C E M_{y}=63.0 \%$ \\
\hline \multirow{3}{*}{8} & & $f_{8}=73.0 \mathrm{~Hz}$ & $f_{8}=80.0 \mathrm{~Hz}$ \\
\hline & & $C E M_{x}=72.2 \%$ & $C E M_{x}=72.3 \%$ \\
\hline & & $C E M_{y}=77.6 \%$ & $C E M_{y}=79.3 \%$ \\
\hline \multirow{3}{*}{10} & & $f_{10}=84.7 \mathrm{~Hz}$ & $f_{10}=89.2 \mathrm{~Hz}$ \\
\hline & & $C E M_{x}=78.6 \%$ & $C E M_{x}=78.3 \%$ \\
\hline & & $C E M_{y}=77.6 \%$ & $C E M_{y}=79.3 \%$ \\
\hline
\end{tabular}

